\title{
Analysis of dynamic changes in retinoid-induced transcription and epigenetic profiles of murine Hox clusters in ES cells
}

\author{
Bony De Kumar, ${ }^{1}$ Mark E. Parrish, ${ }^{1}$ Brian D. Slaughter, ${ }^{1}$ Jay R. Unruh, ${ }^{1}$ \\ Madelaine Gogol, ${ }^{1}$ Christopher Seidel, ${ }^{1}$ Ariel Paulson, ${ }^{1}$ Hua Li, ${ }^{1}$ Karin Gaudenz, ${ }^{1}$ \\ Allison Peak, ${ }^{1}$ William McDowell, ${ }^{1}$ Brian Fleharty, ${ }^{1}$ Youngwook Ahn, ${ }^{1}$ Chengqi Lin, ${ }^{1,3}$ \\ Edwin Smith, ${ }^{1,4}$ Ali Shilatifard, ${ }^{1,4}$ and Robb Krumlauf ${ }^{1,2}$ \\ ${ }^{1}$ Stowers Institute for Medical Research, Kansas City, Missouri 64110, USA; ${ }^{2}$ Department of Anatomy and Cell Biology, \\ Kansas University Medical Center, Kansas City, Kansas 66160, USA
}

\begin{abstract}
The clustered Hox genes, which are highly conserved across metazoans, encode homeodomain-containing transcription factors that provide a blueprint for segmental identity along the body axis. Recent studies have underscored that in addition to encoding Hox genes, the homeotic clusters contain key noncoding RNA genes that play a central role in development. In this study, we have taken advantage of genome-wide approaches to provide a detailed analysis of retinoic acid (RA)-induced transcriptional and epigenetic changes within the homeotic clusters of mouse embryonic stem cells. Although there is a general colinear response, our analyses suggest a lack of strict colinearity for several genes in the HoxA and HoxB clusters. We have identified transcribed novel noncoding RNAs (ncRNAs) and their cis-regulatory elements that function in response to RA and demonstrated that the expression of these ncRNAs from both strands represent some of the most rapidly induced transcripts in ES cells. Finally, we have provided dynamic analyses of chromatin modifications for the coding and noncoding genes expressed upon activation and suggest that active transcription can occur in the presence of chromatin modifications and machineries associated with repressed transcription state over the clusters. Overall, our data provide a resource for a better understanding of the dynamic nature of the coding and noncoding transcripts and their associated chromatin marks in the regulation of homeotic gene transcription during development.
\end{abstract}

[Supplemental material is available for this article.]

The clustered Hox genes encode homeodomain-containing transcription factors that confer segmental identity along the primary body axis of both vertebrates and invertebrates (McGinnis and Krumlauf 1992; Gross and McGinnis 1996). They are highly conserved and functionally implicated in mechanisms controlling the regionalization of the body plan of all bilaterally symmetrical animals (de Rosa et al. 1999). A unique feature of clustered Hox genes is the direct relationship between their chromosomal organization, expression, and function in time and space during development, termed colinearity (Lewis 1978; Duboule and Dollé 1989; Graham et al. 1989; Simeone et al. 1990; Kmita and Duboule 2003). These nested and ordered domains of vertebrate Hox gene expression are coupled to segmentation along the body axis and established during embryogenesis through combinatorial inputs from multiple signaling pathways (Bel-Vialar et al. 2002; Diez del Corral and Storey 2004; Deschamps and van Nes 2005; Wellik 2009; Young et al. 2009; Mallo et al. 2010; Rhinn and Dollé 2012). Conserved axial patterning signals may play a similar role in controlling colinear Hox expression in chordates (Wada et al.

Present addresses: ${ }^{3}$ Institute of Molecular and Cell Biology, A-STAR, 138673 Singapore; ${ }^{4}$ Department of Biochemistry and Molecular Genetics, Northwestern University Feinberg School of Medicine, Chicago, IL 60611, USA

Corresponding author: rek@Stowers.org

Article published online before print. Article, supplemental material, and publication date are at http://www.genome.org/cgi/doi/10.1101/gr.184978.114. Freely available online through the Genome Research Open Access option.
1999; Manzanares et al. 2000; Lowe et al. 2003; Ikuta et al. 2004; Seo et al. 2004; Pani et al. 2012).

Insight into mechanisms establishing domains of Hox expression arises from in vivo analyses of the response of Hox genes to growth factors (Fibroblast Growth Factors [FGFs]) and inducing signals (retinoic acid [RA]) (Conlon and Rossant 1992; Marshall et al. 1992; Isaacs et al. 1998; Pownall et al. 1998; Bel-Vialar et al. 2002). Studies have underscored a key role for RA signaling in transient induction of the early ordered and nested domains of Hox expression in the CNS (Diez del Corral et al. 2003). RA signaling is implicated in early positioning of the anterior boundaries of 3' HoxB genes (paralog groups 1-5) (Marshall et al. 1994; Studer et al. 1998; Bel-Vialar et al. 2002; Sirbu et al. 2005) and later in the rostral expansion of the expression domains of $5^{\prime}$ genes in the cluster (Ahn et al. 2014). Direct input of retinoids on transcriptional activity can be mediated through binding of heterodimeric complexes of retinoid (RAR) and retinoid X (RXR) receptors to retinoic acid response elements (RAREs) (Chambon 1994). These RAREs generally have a short direct repeat sequence motif with a variable spacer of two (DR2) to five (DR5) nucleotides. RAREs recruit coactivators (EP300 and CREBBP), corepressors (NCOR1 and NCOR2), and other protein complexes that have inputs into regulation of epigenetic states and modifiers of chromatin accessibility (Kininis and Kraus 2008; Evans and Mangelsdorf 2014).

() 2015 De Kumar et al. This article, published in Genome Research, is available under a Creative Commons License (Attribution 4.0 International), as described at http://creativecommons.org/licenses/by/4.0/. 
Cis-regulatory analyses have found that the response of Hox genes to RA is mediated in part through the presence of RAREs within Hox clusters (Alexander et al. 2009; Tümpel et al. 2009). Functional RAREs have been identified adjacent to mammalian Hoxd4 (Moroni et al. 1993), Hoxb4 (Gould et al. 1998), Hoxa4 (Packer et al. 1998), Hoxb5 (Sharpe et al. 1998; Oosterveen et al. 2003), Hoxa1 (Langston and Gudas 1992; Dupé et al. 1997), and Hoxb1 (Marshall et al. 1994; Studer et al. 1994, 1998; Ogura and Evans 1995a,b). In vertebrates, dietary deficiency of retinoids and alterations to enzymes controlling the synthesis and degradation of retinoids display a wide variety of defects associated with changes in patterns of Hox expression in the CNS and other tissues (Gale et al. 1999; Niederreither et al. 1999, 2000; Begemann et al. 2001; Grandel et al. 2002; Maden 2002; Linville et al. 2004; Oosterveen et al. 2004; Molotkova et al. 2005; Sirbu et al. 2005; Hernandez et al. 2007; White and Schilling 2008; Rhinn and Dollé 2012). Hox genes also regulate components of retinoid signaling (Aldh1a2/Raldh2 and Rarb) to set up feedback loops that reinforce positive cross-talk between Hox expression and RA signaling (Serpente et al. 2005; Vitobello et al. 2011). In addition to the direct effects of retinoids on Hox expression, RA modulates the expression domains of the $C d x$ transcription factors, and these in turn bind to cis-elements in the Hox clusters to regulate axial expression (Houle et al. 2000, 2003; Lohnes 2003; Young et al. 2009; van de Ven et al. 2011; van Rooijen et al. 2012).

Several studies have demonstrated that teratocarcinoma and embryonic stem (ES) cells can be induced to differentiate upon RA treatment. During this differentiation process, there appears to be a colinear activation of Hox genes, such that the $3^{\prime}$ Hox genes are sequentially activated before $5^{\prime}$ members of the clusters (Simeone et al. 1990, 1991; Papalopulu et al. 1991). This response reflects the underlying signaling mechanisms related to how axial domains of Hox expression are established through the dynamic action of opposing signaling centers during elongation of the vertebrate body axis (Diez del Corral and Storey 2004; Deschamps and van Nes 2005; Young et al. 2009). Hence, understanding the Hox response to RA in ES cells is highly relevant for understanding how retinoid signals contribute to the ordered domains of Hox expression in neural development (Marshall et al. 1994; Itasaki et al. 1996; Gould et al. 1998; Studer et al. 1998; Gavalas and Krumlauf 2000; Gavalas 2002; Serpente et al. 2005).

A variety of protocols are available to differentiate ES cells using signaling molecules, such as RA, FGFs, activin, and R-spondin (Fraichard et al. 1995; Drab et al. 1997; Wobus et al. 1997; Gottlieb and Huettner 1999; Glaser and Brustle 2005; Kawaguchi et al. 2005). Several previous studies of mouse and human ES cells have characterized gene expression and epigenetic events both in Hox clusters and on a genome-wide basis (Chambeyron and Bickmore 2004; Boyer et al. 2005, 2006; Bernstein et al. 2006; Kashyap et al. 2011; Mahony et al. 2011; Gaertner et al. 2012; Mazzoni et al. 2013; Sheikh et al. 2014). The majority of these have focused on events between 24 and $96 \mathrm{~h}$ following RA treatment, using doses of 1-10 $\mu \mathrm{M}$. However, RA concentrations in developing mouse embryos normally range from 16 to $35 \mathrm{nM}$ (Scott et al. 1994; Horton and Maden 1995), and a recent ES cell study has shown that treatments with lower physiological levels of RA more accurately mimic in vivo regulatory events during the early development (Sheikh et al. 2014). In this study, we used $33 \mathrm{nM} 9$-cis retinoic acid in combination with short interval time points in the initial stages of RA-induced differentiation ( $0-24 \mathrm{~h}$ ) to characterize the early transcriptional and epigenetic events associated with expression of both coding and ncRNAs in and around the Hox clusters. We find that ncRNAs from both strands of Hox clusters represent some of the most rapidly induced transcripts in ES cells, and they are associated with dynamic epigenetic changes. At least three of these noncoding regions appear to be directly regulated by RA, and we show coregulation of a ncRNA (Hobbit1) and Hox coding genes in the HoxB cluster is mediated by a shared RAREdependent enhancer.

\section{Results}

\section{RA-induced differentiation of murine ES cells}

We used the programmed differentiation of mouse ES cells to neural fates with RA as a model to investigate the dynamic early expression and epigenetic regulation of Hox clusters. A detailed time course using mouse KH2 ES cells (Beard et al. 2006) was performed to examine the transcriptional activity of coding and noncoding regions in and around the four murine Hox clusters (Fig. 1A). Samples were harvested between 0 and $72 \mathrm{~h}$ after exposure to $33 \mathrm{nM}$ of 9-cis-RA. Affymetrix Mouse Genome 4302.0 arrays were used to monitor global changes in expression profiles, and selected samples were also analyzed by RNA-seq. Applied Biosystems TLDA (Taqman Low Density Array) cards (qPCR), containing probes for the 39 murine Hox genes and five endogenous controls, were used to quantitate changes. To monitor transcription from coding and noncoding regions, we designed custom tiling arrays (Agilent) with probes covering both strands of DNA. These spanned the four Hox clusters and large areas of their flanking DNA up to the adjacent non-Hox coding genes on the $5^{\prime}$ and $3^{\prime}$ sides of each cluster. Applying multiple approaches provided an ability to systematically characterize and validate the qualitative and quantitative changes in the transcriptional profiles of Hox clusters induced by RA during early differentiation of ES cells.

We first evaluated the differentiation process based on global changes in gene expression (Supplemental Table S1). Affymetrix data were analyzed for genes showing twofold or more changes in expression levels compared to untreated ES cells using hierarchical clustering and displayed as a heatmap (Fig. 1B). Six clusters, identified by $k$-means clustering, show maximum mean changes in gene expression with distinct induction profiles (Supplemental Fig. S1A,B). Gene Ontology (GO) term analyses of expression profiles indicate that RA progressively drives cells toward a neuroectodermal fate (Supplemental Fig. S1C). This is reflected by the up-regulation of a large number of genes related to developmental processes and neurogenesis in concert with the down-regulation of genes related to stem cell development and maintenance, along with negative regulators of cell differentiation. Cluster 1 contains rapidly induced genes expressed upon RA treatment (e.g., Cyp26a1, Rarb, Crabp2, and Cdx1) (Fig. 1B), whose functions are associated with pattern specification processes and commitment of these cells to a neuronal fate (Supplemental Fig. S1). Hox genes (e.g., Hoxb1, Hoxa1, and Hoxa5) and genes for their cofactors (e.g., Meis2) are highly represented in this cluster of rapidly induced genes. These data reveal that the RA-induced differentiation of KH2 ES cells shows a general pattern of gene regulation similar in many aspects to early in vivo phases of the neural development process.

\section{Monitoring the cellular response to RA}

To investigate the level of uniformity of the response of ES cell populations to RA treatment, we used a fluorescence in situ hybridization (FISH) approach for single RNA molecules (Stellaris FISH

\section{Genome Research}

www.genome.org 
A

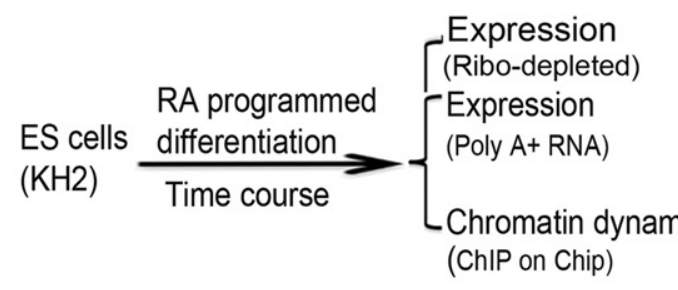

\section{C}

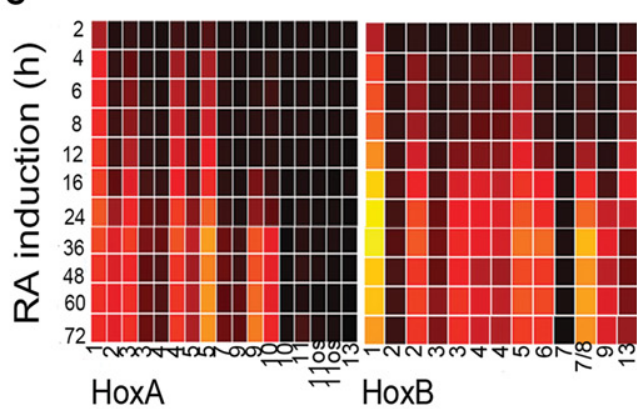

HoxA

\section{D}

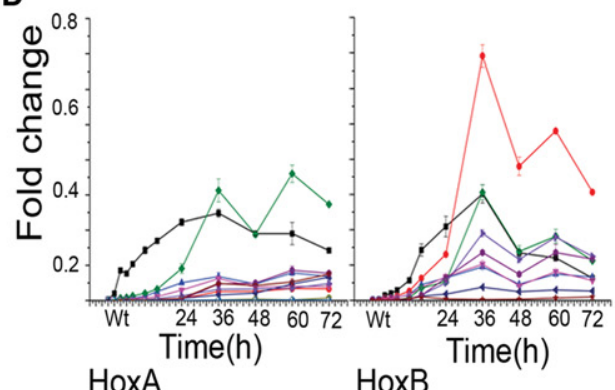

HoxA

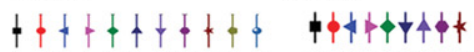

$12345679101113 \quad 1245678913$

\section{E}

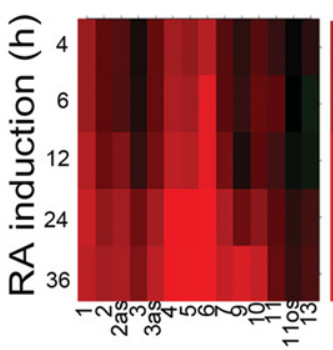

HoxA

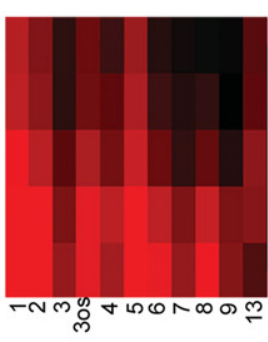

HoxB
RNA-Seq

Tilling Array Affymetrix Array qPCR

Histone modifications (H3K4me3, H3K27me3)

Regulators of transcription (Pol II,RARs,SUZ12,NCOR)
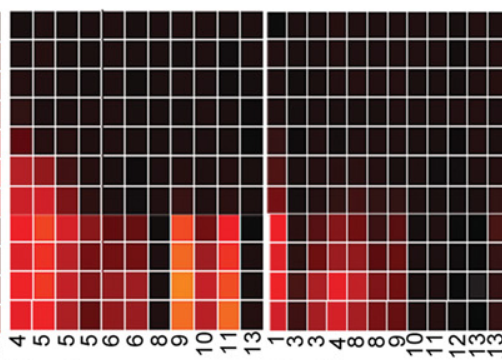
$\mathrm{HoxC}$ HoxD

Fold change

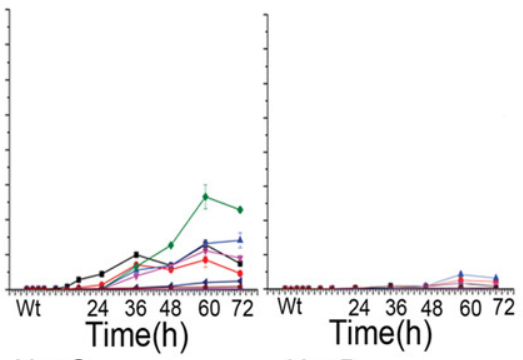
$\mathrm{HoxC}$

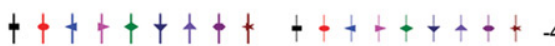

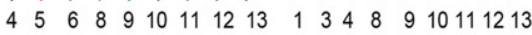
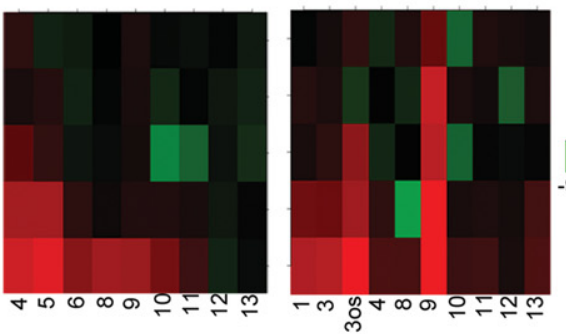

HoxC
B
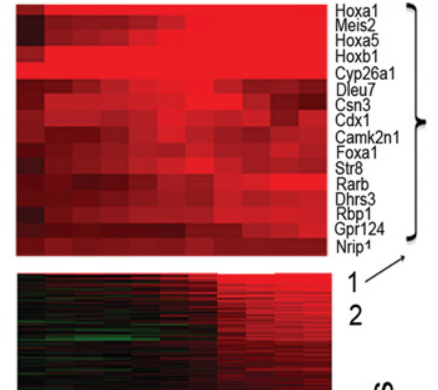

2

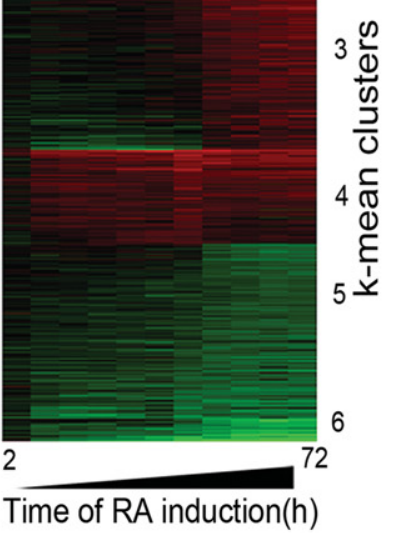

-5 Fold change 5

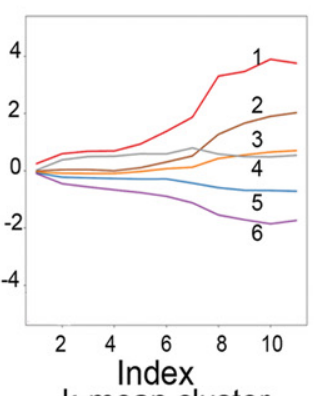

k-mean cluster

Figure 1. Analysis of changes in Hox and global gene expression during RA-induced differentiation of mouse ES cells. $(A)$ Flow chart outlining overall experimental strategy. (B) Heatmap showing global changes in gene expression upon RA induction compared with uninduced ES cells as analyzed on Affymetrix Mouse Genome 4302.0 arrays. The lower panel shows the distinct induction profiles of six clusters, identified by $k$-means clustering. Expression values are the average value from three independent biological replicates. The middle panel displays a heatmap of global changes in gene expression upon RA-induced differentiation; $k$-means clusters are indicated on the right. Only clusters with an absolute value of cluster mean $>0.5$ are shown. The upper panel shows changes in the expression profile for 15 of the most rapidly induced genes in cluster 1 , which includes Hox genes and genes for the cofactors (Meis). (C) Heatmap of relative changes in Hox gene expression upon RA induction compared with uninduced ES cells as analyzed on Affymetrix Mouse Genome 4302.0 arrays. Genes in the HoxA and HoxB clusters display a more rapid and robust induction than those of the HoxC and HoxD clusters. Several genes have multiple probes, and results are shown for each. $(D)$ Temporal changes in Hox gene expression induced by RA quantitated by TLDA qPCR microfluidics cards. All data points are the average of three biological and two technical replicates. The $y$-axis in all clusters is shown on the same scale and illustrates relative levels of induction between Hox clusters. (E) RNA-seq analysis of Hox gene expression in RA treated ES cells compared to uninduced cells. Fold changes are shown as a heatmap. 
protocol) developed by Biosearch Technologies (Femino et al. 1998; Raj and Tyagi 2010). This enables us to measure the fraction of cells responding to RA treatment. Cyp26a1 is the most rapidly induced gene, displaying significant induction within $2 \mathrm{~h}$ of RA treatment, and it accumulates high levels of transcripts (Fig. 1B). Therefore, we used it to monitor the efficiency of the RA response. Compared to uninduced ES cells, at $4 \mathrm{~h}$ of RA treatment, which is early in the induction process, a majority (83\%) of the cells already display a significant Cyp26a1 signal (Fig. 2; Supplemental Fig. S2). By $24 \mathrm{~h}$, there is a modest additional increase in the fraction of pos- itive cells ( $<94 \%)$ and a major increase in the levels of expression in each cell. We independently validated these results using another single molecule FISH approach, Hybridization Chain Reaction (HCR) (Choi et al. 2010, 2014). HCR analysis with Cyp26a1 reveals a comparable fraction of positive cells at both $4 \mathrm{~h}(80 \%)$ and $24 \mathrm{~h}(93 \%)$ and similar levels of expression per cell (Fig. 2; Supplemental Fig. S2). These data indicate that the KH2 cells efficiently show a rapid and uniform response to RA, indicating the absence of a major subpopulation of cells resistant to RA or with a delayed response.

Hoxa1 and Hoxb1 are also induced early, but they appear after Cyp26a1 and at much lower levels (Fig. 1B). These lower levels of expression create a challenge for sensitivity of detection by FISH; nonetheless we compared the expression of Hoxa1, Hoxb1, and Cyp26a1 at 4 and $24 \mathrm{~h}$ time points of RA treatment with uninduced ES cells. In accord with results using the single probe sets, multiplex in situ hybridization with two different Stellaris probe sets (Cyp26a1/Hoxa1; Cyp26a1/Hoxb1) revealed a comparable fraction of cells positive for Cyp26a1 at $4 \mathrm{~h}(70 \%-80 \%)$ and $24 \mathrm{~h}(81 \%-87 \%)$ of RA induction. For Hoxa1, 43\% of cells scored as positive at $4 \mathrm{~h}$ and $51 \%$ at 24 $h$, and levels of expression per cell were similar at the two time points. This correlates with the early induction and rapid plateau in levels of Hoxa1 observed in the expression profiling and qPCR (Supplemental Fig. S3). For Hoxb1, 22\% and $55 \%$ of cells display expression at 4 and $24 \mathrm{~h}$, respectively, in agreement with the kinetics of the Hoxb1 induction profile observed by qPCR. Despite the challenges in sensitivity, at $4 \mathrm{~h}$, a significant proportion of the cells display detectable levels of Hoxa1 and Hoxb1, respectively. The lower fraction of Hoxa1 and Hoxb1 positive cells at these time points compared to Cyp26a1 directly correlates with their lower levels of expression and differences in induction kinetics. Correlation plots of the double label experiments show that nearly all of the Hoxa1 or Hoxb1 positive cells also display a signal for Cyp26a1 (Fig. $2)$, showing they are not separate populations. These results support the idea that the majority of uninduced $\mathrm{KH} 2$ ES cells rapidly respond to RA, based on the high fraction of cells positive for Cyp26a1 at $4 \mathrm{~h}$, and then undergo a progression through the differentiation program, which results in increased levels of expression of Cyp26a1, Hoxa1, and Hoxb1 over time. A much larger fraction of the cells are likely positive for Hoxa 1 and Hoxb1, but they fall below the level of detection thresholds. 


\section{Temporal dynamics of transcriptional activity in Hox complexes}

In general agreement with the property of colinearity observed in embryonic development and cellular response to RA (Simeone et al. 1990; Papalopulu et al. 1991; Bel-Vialar et al. 2002; Kmita and Duboule 2003; Alexander et al. 2009), the Affymetrix expression profiling reveals that the order of genes in a Hox cluster tends to temporally correlate with their response to RA (Fig. 1C). The detailed time course of RA-induced differentiation allowed us to capture the induction kinetics of genes within each cluster. The HoxA and $H o x B$ clusters display a more rapid and stronger response to RA than the HoxC and HoxD clusters, presumably because the HoxC and HoxD clusters correlate more with posterior genes and later programs of embryogenesis (Fig. 1C). Surprisingly, a strict pattern of temporal colinearity was not followed by some Hox genes in the HoxA and HoxB clusters. For example, expression of Hoxa5 is observed earlier than that of Hoxa 2 and Hoxa3, and Hoxb5 is detected earlier than Hoxb3 and Hoxb4 (Fig. 1C). We independently validated these induction profiles by performing quantitative PCR (qPCR) using Applied Biosystems TLDA cards with Hox probes and RNAseq (Fig. 1D,E; Supplemental Fig. S3). Both assays reveal a similar order of induction, relative levels of gene expression, and variations of strict colinearity, confirming the Affymetrix results. It is worth noting that these observations are based on steady-state levels of mRNA and do not account for possible differences in factors such as RNA stability or transcriptional efficiency of promoters.

\section{Global transcriptional activity of Hox clusters}

Evidence for lack of strict colinearity in HoxA and HoxB in response to RA via Affymetrix arrays and qPCR led us to further investigate the nature of the transcriptional profiles spanning the four Hox clusters with other methods to avoid concerns about cross hybridization and inability to detail novel transcript isoforms. Therefore, we designed custom tiling arrays that contain probes covering both strands of DNA spanning the four Hox cluster regions and large areas of their flanking DNA, up to the adjacent non-Hox coding genes on the $5^{\prime}$ and $3^{\prime}$ sides of the clusters. We utilized RNA from the same samples in the time course of programmed differentiation and compared expression levels with undifferentiated ES cells to calculate the fold levels of induction. A heatmap indicating relative levels and chromosomal position of transcripts over the time course of RA treatment reveals a complex and dynamic pattern of transcription (Fig. 3). This detailed temporal analysis allowed us to capture small differences in induction kinetics of genes within each cluster and again revealed the same specific differences in temporal colinearity. The relative order and levels of induction of expression over coding regions correlates very well with the expression patterns obtained by Affymetrix and qPCR analyses (Figs. 1, 3).

The induction profiles indicate a high degree of transcriptional activity from noncoding regions in and around the Hox clusters from both sense and antisense strands. Upon induction, extensive intergenic (noncoding) transcription is observed in the HoxA and

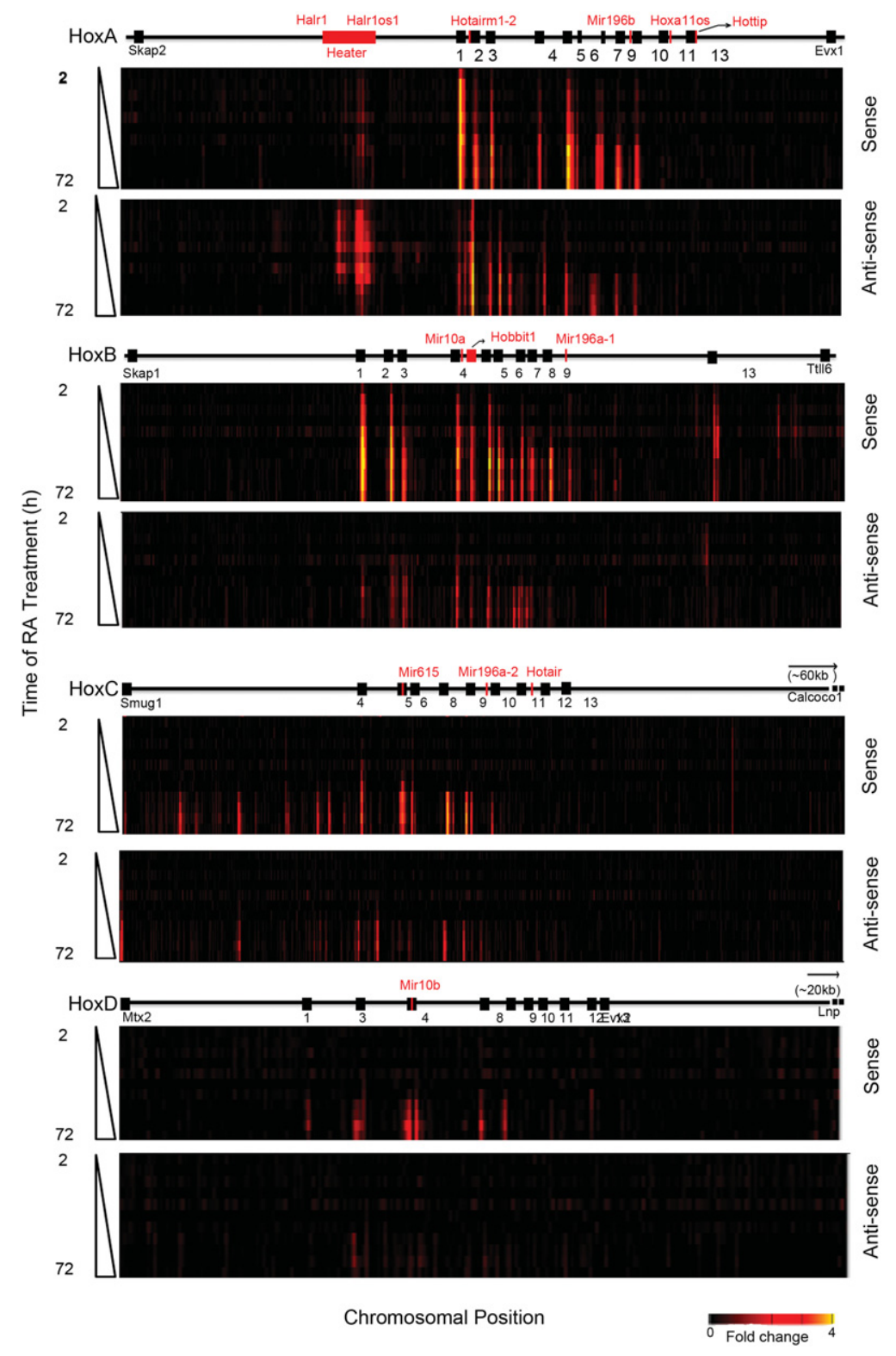

Figure 3. Global transcriptional activity in and around the four Hox clusters analyzed by Agilent tiling arrays. Heatmap showing global changes in gene expression over the time course of RA induction compared with uninduced ES cells as analyzed on custom Agilent $2 \times 105 \mathrm{~K}$ Hox tiling arrays. mRNA is labeled with Cy3. Heatmaps are generated on the Integrative Genomics Viewer (IGV) 1.5, where intensity of heat represents relative expression level. Upper and lower panels in each cluster represent sense and antisense strands, respectively. The $x$-axis denotes the chromosomal position and location of respective Hox genes and ncRNAs. The $y$-axis denotes the length of RA treatment in $\mathrm{h}$. 
HoxB clusters, whereas a lower degree of activity is observed in HoxC. The HoxD cluster displays no intergenic transcriptional activity at the time points examined (Fig. 3). We observe many previously known noncoding transcripts (Hotairm1, Halr1, mir-10a, mir-10b, mir196a-1, and mir196b) but a large number of novel or unknown transcripts are uncovered in this analysis (Fig. 3; Supplemental Fig. S4). For example, we identified a rapidly induced transcript positioned between Hoxb4 and Hoxb5 on the coding strand and named it Hobbit1 (HoxB4-B5 intergenic transcript1). The expression of several previously characterized ncRNAs, such as Hottip and Hotair, are not detected. This is likely due to timing, as posterior genes in the HoxA and $\mathrm{HoxC}$ clusters are weakly expressed even after $72 \mathrm{~h}$ of RA induction, in accord with their roles in later programs of embryonic development.

There is also induction of a series of noncoding transcripts immediately adjacent to the $\operatorname{HoxA}, \mathrm{HoxB}$, and $\mathrm{HoxC}$ clusters (Fig. 3). Positioned $\sim 50 \mathrm{~kb} 3^{\prime}$ of Hoxa1, we observe a large region ( 15 $\mathrm{kb})$ that gives rise to multiple spliced transcripts (at least eight) from both strands of DNA. These transcripts are named Halr1 (isoforms 1-6) and Halr1os1 (isoforms 1 and 2) (Supplemental Table S7). This includes the three previously identified transcripts, now known as Halr1 (isoforms 1-3), found in genome-wide studies of uninduced ES cells (Guttman et al. 2010; Maamar et al. 2013). In uninduced ES cells, there is a low level of transcripts detectable throughout this region, and a rapid increase in transcriptional activity upon RA treatment. We collectively named this region Heater (HoxA EArly Transcribed REgion), to designate this dynamic early transcriptional activity near the HoxA cluster (Fig. 3, 4A). In the $5^{\prime}$ region flanking $\operatorname{HoxB}$, there are a series of weakly expressed early induced transcripts on the sense strand spread throughout the intergenic region between Hoxb13 and Ttll6. The 3' flanking region between Hoxc4 and Smug1 displays a distinct series of intergenic transcripts from the sense strand that appear at later times of induction (after 24-36 h).

We further investigated and validated the transcriptional profiles using RNA-seq (Supplemental Fig. S4; Supplemental Tables S2, S3). This allowed us to quantitate the amount of transcripts generated by these sequences. A number of transcripts are detected in uninduced $\mathrm{KH} 2$ cells, including Halr1 (isoforms 1-3) and Rps8ps3 from HoxA and Gm11539 from HoxB clusters. Heater derived transcripts, Hotairm1, Hotairm2, Hoxb3os, Hobbit1, and Rps8-ps3 are highly induced by RA treatment, and Gm11539 is slightly down-regulated. The steady state levels of these ncRNAs in both uninduced and RA treated ES cells are significantly higher than their neighboring Hox genes (Supplemental Tables S2, S3). This suggests that these ncRNAs are unlikely to reflect run-off transcripts or low levels of background transcription. There are many other ncRNAs on both stands transcribed at a low to moderate level. This highlights an unexpected degree of complexity in the global transcriptional activity in and around Hox clusters in addition to the coding regions that needs to be considered in evaluating the regulation of the clustered Hox genes.

\section{Retinoid receptor occupancy in Hox clusters}

To explore the nature of the transcriptional response to RA, we analyzed dynamic occupancy of retinoid receptors RARA, RARB, RARG, RXRA, and their associated corepressors NCOR1 and 2 on Hox clusters. In the HoxA cluster, there is a surprisingly large region extending from Hoxa 1 to Hoxa3, including Hotairm 1 and Hotairm2, which displays a high level of occupancy of all three RARs but not RXR in undifferentiated cells (Fig. 5; Supplemental
Fig. S5). There is also a low level of NCOR binding to this region. There is a dramatic and rapid change in the profile over this region by $2 \mathrm{~h}$, with the broad loss of occupancy of RARA, RARB, RARG, and the recruitment of RXRA (Fig. 5). At 2 and $24 \mathrm{~h}$, RARA, RARB, and RARG occupy other select focused regions in the HoxA cluster.

The dynamic patterns of occupancy over the HoxB cluster are very different (Fig. 5). There is a well-characterized set of RAREs around Hoxb1 (Tümpel et al. 2009), and we observe occupancy of the RARs, RXRA, and NCOR over these elements in undifferentiated ES cells. Upon RA treatment, there is very little change in the occupancy profiles in these Hoxb1 flanking regions, with the exception of expanded recruitment of RARG. In uninduced cells, we also observe a low level of occupancy of RARA, RARB, and RARG in the Hoxb4-Hoxb5 intergenic region, which harbors several previously characterized RAREs involved in long-range regulation of multiple Hox genes, including Hoxb4 and Hoxb5 (Gould et al. 1997, 1998; Sharpe et al. 1998; Oosterveen et al. 2003; Ahn et al. 2014). At $2 \mathrm{~h}$, there is a dramatic gain RARA occupancy (Fig. 5; Supplemental Fig. S6). The RARA occupancy decreased by $24 \mathrm{~h}$ of RA treatment and is replaced by increased binding with RARG. This type of RARA-RARG switch has been observed in the differential utilization of retinoid receptors during early versus late stages of embryonic development and ES cell differentiation (Gillespie and Gudas 2007; Kashyap et al. 2011). The rapid recruitment of RARA in the intergenic region between Hoxb4 and Hoxb5 correlates with Hobbit1 transcription and its rapid response to RA (Supplemental Fig. S6). These results reveal distinctly different dynamics of RAR occupancy in the HoxA and HoxB clusters. Consistent with their weak RA response, the HoxC and HoxD clusters show very little occupancy in uninduced cells or sustained changes during the first $24 \mathrm{~h}$ of differentiation (Supplemental Fig. S8).

\section{Rapid induction of noncoding transcripts from Hox clusters}

Many of these ncRNAs display distinct induction kinetics, some of which are as rapid and as strong as the earliest induced Hox genes. The Hobbit1 transcript between Hoxb4 and Hoxb5 begins to be induced at $4 \mathrm{~h}$ of RA treatment in a manner that parallels Hoxb4 and Hoxb5 and is also expressed in the embryo (Fig. 3; Supplemental Fig. S6; Supplemental Tables S2-S4). However, the absolute levels of expression of Hobbit1 are 10 -fold higher than Hoxb4 and Hoxb5 throughout the differentiation time course.

We found a cluster of three partially overlapping transcripts between Hoxa1 and Hoxa2 (Supplemental Fig. S5), one of which corresponds to the previously characterized human HOTAIRM1 generated from the noncoding strand and involved in myelopoiesis (Zhang et al. 2009). We identified a new splice-variant for Hotairm1 and a novel transcript (Hotairm2), which partially overlaps with HOTAIRM1 and Hoxa1. The tiling arrays, qPCR and RNA-seq reveal that Hotairm1 and Hotairm2 transcripts are some of the most rapidly induced RNAs, showing a significant induction by 2 h, similar to Hoxa1 (Fig. 3; Supplemental Fig. S5C; Supplemental Tables S3, S4). These Hotairm1 and Hotairm2 transcripts are expressed in early mouse embryos $(7.75 \mathrm{dpc})$ and decrease to low levels by $9.5 \mathrm{dpc}$, resembling the kinetics of endogenous Hoxa1 expression (Supplemental Fig. S5D; Supplemental Table S3). ENCODE data (Rosenbloom et al. 2013) suggest that these transcripts are present in several adult tissues, such as fat pads, heart, kidneys, and spleen.

The Heater region generates a complex series of transcripts from different promoters, many with very rapid induction kinetics,

\section{Genome Research}

www.genome.org 
appearing around the same time as Hoxa1 (Fig. 3). This also makes Heater RNAs among the earliest Hox cluster associated transcripts induced by retinoids. Using a combination of informatics, primer walking, and 5' RACE, we cloned and characterized eight distinct spliced and polyadenylated transcripts from Halr1 and Halr1os1 (Fig. 4A; Supplemental Table S7). The region in Heater most proximal to Hoxa1 also generates a high level of unspliced transcripts. The antisense strand of Heater is transcribed at a higher level compared to the sense strand. Analysis (qPCR) of the individual Heater transcripts (except isoform 6) reveals that all of them display a modest level of induction between 2 and $6 \mathrm{~h}$, but at later time points, there are large differences in the dynamics of individual transcript profiles (Figs. 3, 4; Supplemental Fig. S4; Supplemental Tables S2-S4). Heater transcripts (Halr1; isoforms 1-3) and Halr1os1 (isoform 2) are expressed at high levels in uninduced $\mathrm{KH} 2$ cells and show a strong inductive response to RA. Individual Heater transcripts also display distinct and dynamic temporal expression profiles in developing mouse embryos (Fig. 4C). ENCODE analyses from the Heater region suggest transcription from adult tissues.

To explore whether retinoid signaling has roles in the induction of the Heater, Hotairm1, Hotairm2, and Hobbit1 noncoding transcripts in developing embryos, we investigated their ability to respond to RA in vivo. Mouse embryos (9.25 dpc) exposed to exogenous RA for $8 \mathrm{~h}$ by gavage treatments reveal that all transcripts display a significant upregulation in response to RA (Fig. 4D). Together, these results indicate that the majority of these intergenic and noncoding transcripts have distinct quantitative and qualitative expression profiles in some way modulated by retinoids.

\section{Regulation of ncRNAs by retinoids}

Next, we investigated how RA might regulate these ncRNAs. Three retinoic acid response elements (RAREs) are positioned in and around Hoxb4 and Hoxb5 (Supplemental Fig. S6A), and they are involved in regulating the expression of multiple $H \circ x B$ genes, including both Hoxb4 and Hoxb5 (Gould et al. 1998; Sharpe et al. 1998; Oosterveen et al. 2003; Ahn et al. 2014). This raised the possibility that the Hobbit1 transcript is directly induced by RA through one or more of these RAREs. To functionally test this idea, we measured the levels of Hobbit1 transcripts in response to RA in neural tissue
A

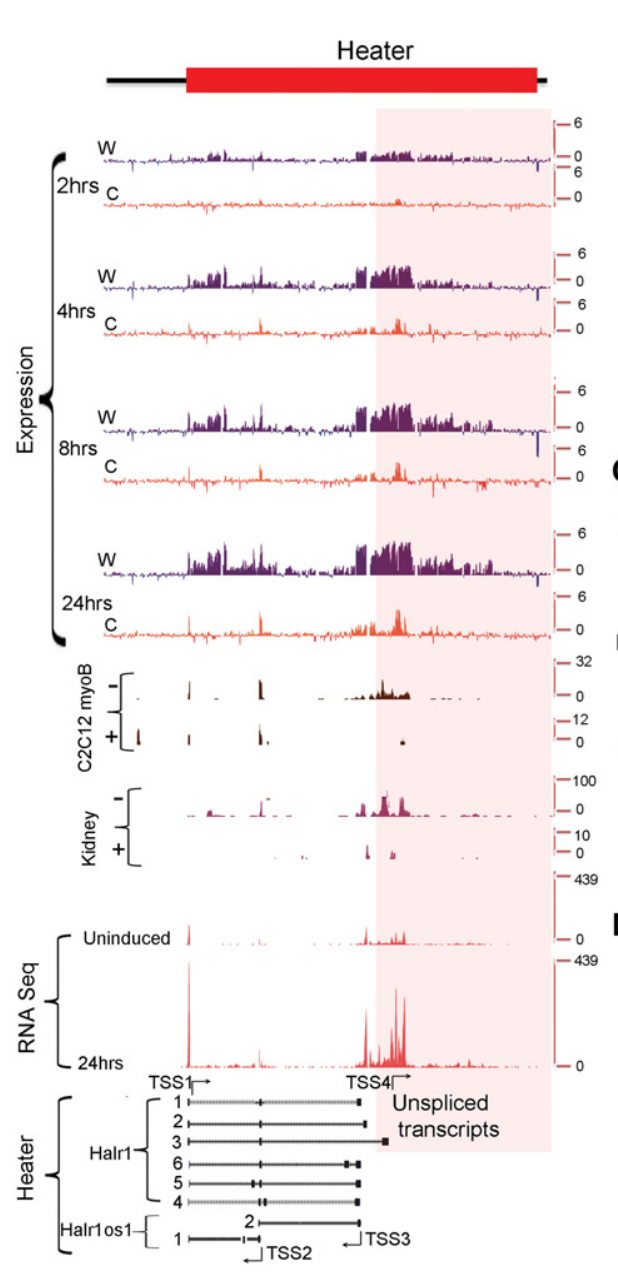

B

Heater and

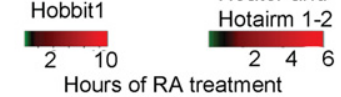

$\begin{array}{llllllllll}2 & 4 & 6 & 8 & 12 & 24 & 36 & 48 & 60 & 72\end{array}$

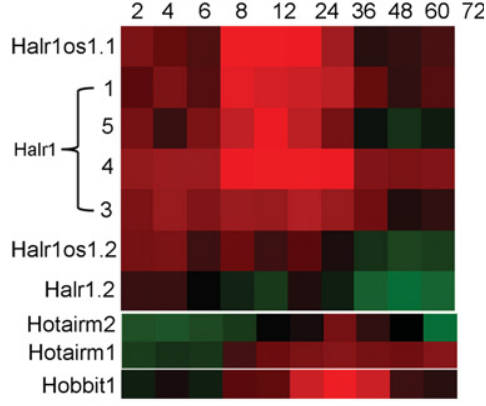

C

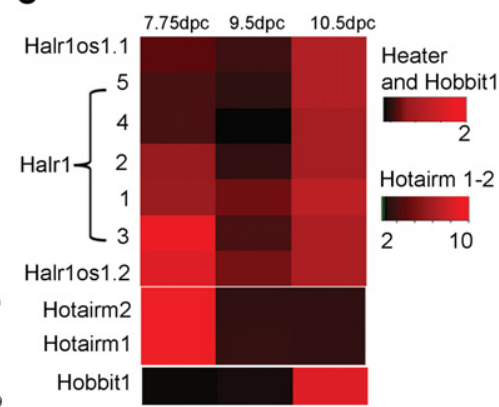

D

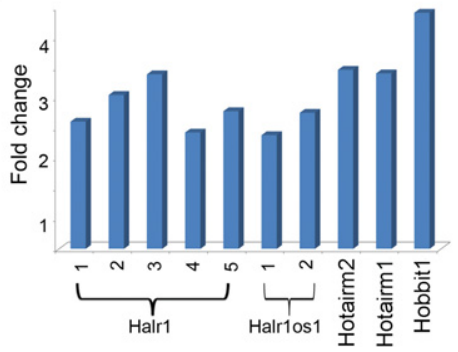

Figure 4. Characterization of Heater (HoxA EArly Transcribed REgion) transcripts. $(A)$ Transcription from the Heater region analyzed by tilling arrays, RNA-seq, and ENCODE. The top of the panel shows rapid induction of Heater transcripts between 2 and $24 \mathrm{~h}$ of RA treatment detected by tiling array profiles. W and $C$ represent Watson and Crick strands, respectively. In the middle of the panel is evidence of Heater expression in adult kidney and cultured cells based on ENCODE data. + and - indicate opposing strands. RNA-seq data in uninduced and 24-h RA-treated ES cells validate expression profiles observed in tiling arrays. At the bottom, multiple Heater transcripts, from Halr1 and Halr1os1, are shown schematically with the respective transcription start sites (TSS) and direction of transcription as indicated by arrows. The pink box denotes a region with a large number of unspliced transcripts generated from TSS4. (B) Heatmap of qPCR quantitation of Halr1, Halr1 os1, Hotairm1, Hotairm2, and Hobbit1 transcripts in RA-induced ES cells. Levels of transcripts are compared against respective transcript levels in uninduced ES cells. Heater, Hotairm1, and Hotairm2 are induced at comparable levels, whereas Hobbit1 shows a higher level of induction in RA-induced differentiation. (C) Heatmap of qPCR quantitation of Halr1, Halr1os1, Hotairm1, Hotairm2, and Hobbit1 transcripts in developing mouse embryos. Levels of transcripts are compared against respective transcript levels in $10 \mathrm{dpc}$ embryo. Heater and Hobbit1 are induced at comparable levels, whereas Hotairm 1 and Hotairm2 show higher levels of induction during mouse embryonic development. Green represents down-regulation; red shows up-regulation. (D) Response of Halr1, Halr1 os 1, Hotairm1, Hotairm2, and Hobbit1 to RA in mouse embryos. The relative response to RA is calculated as fold change in transcript level after treating $10.0 \mathrm{dpc}$ mouse embryos with RA compared to untreated mouse embryos at the same stage.

of a mouse embryo carrying a targeted deletion of the DE-RARE (Ahn et al. 2014) and found a significant reduction in expression (Supplemental Fig. S6D). This shows that the DE-RARE is a shared cis-regulatory element required in vivo for regulating the proper levels of Hobbit1 and Hoxb4-Hoxb5 expression in developing 
mouse embryos. Further supporting this idea, chromatin immune precipitation (ChIP) assays using the tiling arrays indicate that RARA recruitment throughout this intergenic region increases dramatically within $2 \mathrm{~h}$ of RA treatment (Supplemental Fig. S6A). In an analogous case, an RARE located 3' of Hoxa1 is required for early activation of the gene in neural tissue (Langston and Gudas 1992; Dupé et al. 1997). This RA-dependent enhancer may also be responsible for the rapid activation of the Hotairm1 and Hotairm2 transcripts as their TSS are near those of Hoxa1.

We investigated potential direct roles for regulation of Heater activity by retinoids using ChIP for RARs and NCOR as a potential means to decipher early RA cis-regulatory inputs. We observed two distinct RAR/RXR and NCOR binding domains flanking Heater, which we refer to as Heater-Associated Regions (H-AR). H-AR1 is a large region (2.6 kb) located upstream of TSS1, whereas $\mathrm{H}$ AR2 is positioned downstream from TSS4. Both these domains display a high level of occupancy of RARA, RARB, RARG, RXRA, and NCOR in both uninduced and induced cells (Fig. 6A). In regions flanking these $\mathrm{H}$-ARs are distinct smaller domains that also display evidence for dynamic changes in the occupancy of some of these receptors (Fig. 6A; Supplemental Fig. S7). It is interesting that the occupancy of NCOR shows only modest changes within the first 24 $\mathrm{h}$ period. This is consistent with mounting evidence from genome-wide studies that argues against the simple general model whereby the activity of bound $\mathrm{RAR} / \mathrm{RXR}$ receptors is gated by the occupancy of corepressors, such as NCOR (Mahony et al. 2011; Evans and Mangelsdorf 2014). Therefore, the persistence of NCOR over Heater (Fig. 5; Supplemental Fig. S7) and areas of the Hox clusters (Fig. 5 ) is consistent with the idea its occupancy does not necessarily correlate with activity state.

We analyzed the H-ARs for the presence of putative RAREs (Sandelin and Wasserman 2005) and find multiple direct repeat (DR) consensus binding sites spread through the region (Fig. 6A; Supplemental Fig. S7B). There is a highly conserved block of sequence shared with human, rat, orangutan, horse, and dog overlapping the $5^{\prime}$ region of the TSS1 Heater transcripts and extending $2.3 \mathrm{~kb}$ upstream into the $3^{\prime}$ end of the large RAR/RXR-bound region. Throughout the RAR/RXR-bound region, there are a series of smaller blocks of sequence conservation. These putative RAREs in RAR/RXR-bound regions suggest a direct role in rapid activation of transcripts from the Heater region. Intriguingly, a recent study has speculated that Halr1 (isoforms 1-3) transcripts from the Heater region may be important for potentiating the response of Hoxa1 to retinoids (Maamar et al. 2013).

\section{Temporal epigenetic changes in Hox clusters}

We examined how the transcriptional activity in Hox clusters correlated with epigenetic changes in chromatin during RA-

\section{Genome Research}

www.genome.org 


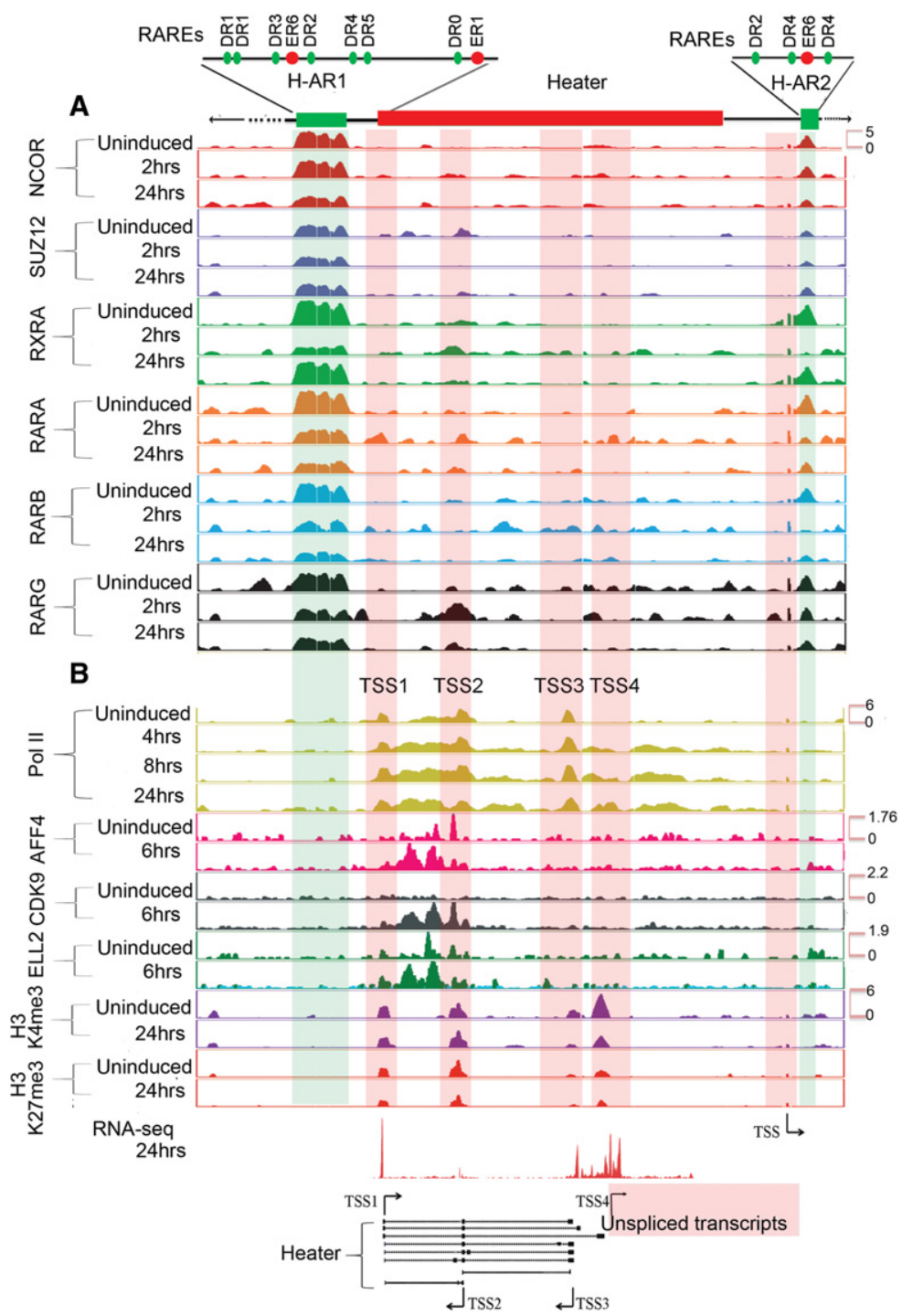

Figure 6. Analysis of changes in the epigenetic state and retinoid receptor occupancy in and around the Heater region during RA-induced differentiation. $(A)$ Occupancy of retinoic acid receptors (RXRA, RARA, RARB, and RARG) and the NCOR corepressor in and around the Heater region. ChIP-on-chip analysis shows a large 2.5-kb region (H-AR1) bound by RAR/RXRs and NCOR upstream of Heater and a smaller domain (H-AR2) region downstream from uninduced and RA-treated ES cells. The schematic at the top shows the relative positions of these regions to Heater and the relative positions of predicted consensus Direct Repeat motifs recognized by retinoid receptors (see Supplemental Fig. S7). (B) Dynamic occupancy of Pol II and components of an elongation complex in the Heater region. H3K27me3 is used as a repressive mark, $\mathrm{H} 3 \mathrm{~K} 4 \mathrm{me} 3$ is used as a mark for promoters and active chromatin state, and Pol II is used as a mark of active transcription. Along with Pol II, a bivalent mark formed by H3K4me3 and H3K27me3 is noticeable over TSS1-TSS4. There is a rapid recruitment of the transcription elongation factors (ELL2, AFF4, and CDK9) upon RA induction. Tracks were configured by using a windowing function as mean and smoothing windows as 10 pixels. At the bottom, multiple Heater transcripts are shown schematically with the respective transcription start sites (TSS) along with RNA-seq at $24 \mathrm{~h}$. The direction of transcription is indicated by arrows. The pink box denotes a region with a large number of unspliced transcripts generated from TSS4. A putative TSS is also apparent in the H-AR2 region.

induced differentiation. The dynamic nature of the noncoding transcriptional profiles of the Hox clusters raises the possibility that they have potential inputs in shaping or responding to epigenetic modifications of chromatin. Toward this goal, we performed ChIP-on-chip assays over a time course of differentiation. Antibodies were used against (1) H3K27me3, a repressive mark; (2) SUZ12, a member of the PRC2 complex and a mark of chroma- tin silencing; (3) H3K4me3, a mark for active chromatin state; and (4) Pol II, a mark of active transcription.

In accord with published studies (Boyer et al. 2006; Lee et al. 2006; Soshnikova and Duboule 2008; Kashyap et al. 2011), in undifferentiated ES cells, the distribution of the H3K27me3 and SUZ12 repressive marks are widely spread over all four Hox complexes (Figs. 5, 7; Supplemental Fig. S8). These marks of a repressed state appear to be confined to the regions spanning the coding genes and are not observed in $3^{\prime}$ or $5^{\prime}$ flanking regions immediately adjacent to the clusters. The one exception is a peak of SUZ12 occupancy over H-AR1 (Figs. 5, 6). This is consistent with the need to maintain Hox genes in a silent or inactive state to prevent them from inducing differentiation of these pluripotent cells.

Over the initial $24 \mathrm{~h}$ period of RA treatment, there is a progressive decrease in the levels of $\mathrm{H} 3 \mathrm{~K} 27 \mathrm{me} 3$ over the most 3 ' genes, Hoxa1 and Hoxb1 (Figs. 5, 7). However, surprisingly, this epigenetic mark remains over many of the genes in the HoxA and HoxB clusters (Figs. 5, $7)$, despite the fact that nearly all of the genes are expressed at $24 \mathrm{~h}$ (Figs. 1, 3). This repressive mark is slowly erased with longer RA treatments and nearly gone by $36 \mathrm{~h}$ (Figs. 5, 7). A similar temporal pattern for the removal of $\mathrm{H} 3 \mathrm{~K} 27 \mathrm{me} 3$ is also observed for the $\mathrm{HoxC}$ and HoxD clusters (Supplemental Fig. S8). Consistent with the results for Hox clusters, we also noted a similar delayed removal of this H3K27me3 mark over the rapidly induced and highly expressed Cyp26a1 gene (Supplemental Fig. S9), indicating that this observation is not restricted to Hox clusters.

We expected the H3K27me3 mark would reflect progressive changes in PcG occupancy that tightly correlated with activation of Hox expression. This led us to look at the occupancy of SUZ12, a component of PRC2, as an alternative means of monitoring PcG-mediated repression and its correlation with gene activity. Focusing on the transcription start sites (TSS) of the Hox genes, we observe a reduction in the SUZ12 occupancy in the vicinity of the TSS at $2 \mathrm{~h}$ of RA treatment for the rapidly induced 3' Hox genes, such as Hoxa1 and Hoxb1 (Fig. 7B). Genes in the middle of the cluster, paralogous groups 3-5, begin to display changes in SUZ12 occupancy at $2 \mathrm{~h}$ that correlates with their induction profiles (Supplemental Fig. S9). The more posterior genes, such as Hoxa9 and Hoxb9, do not show a reduction at $2 \mathrm{~h}$, but display a marked change in occupancy by $24 \mathrm{~h}$ (Fig. 7). 
A

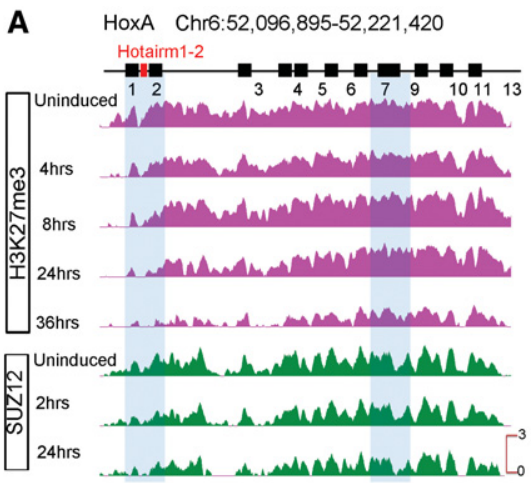

HoxC Chr15:102729801-102875567
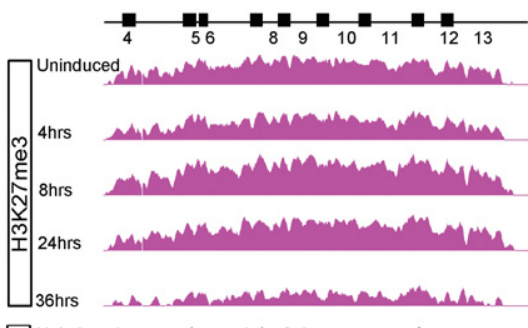

2hrs $24 \mathrm{hrs}$

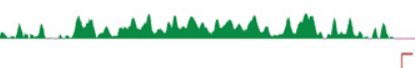

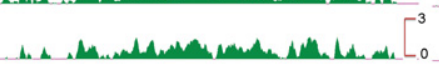
${ }_{-3}^{1}$

B Hoxa1

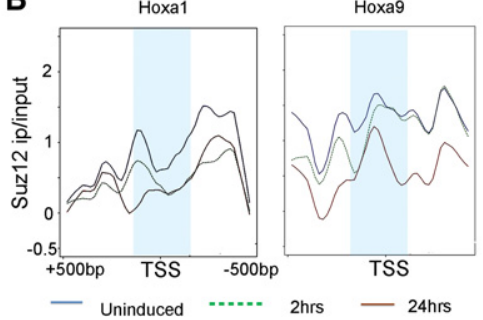

HoxB Chr11:96,046,362-96,240,188

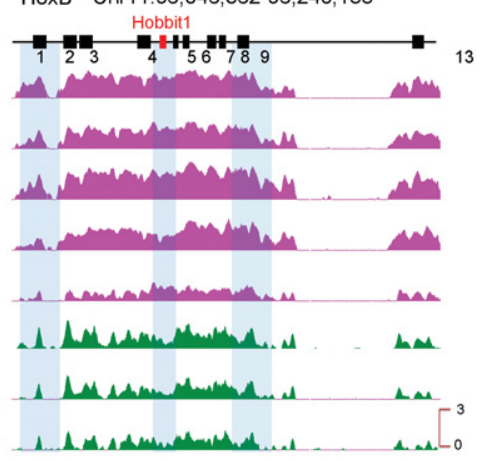

HoxD Chr2:74,502,755-74,605,213
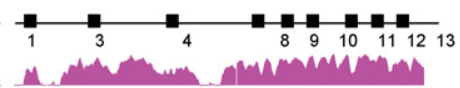

(

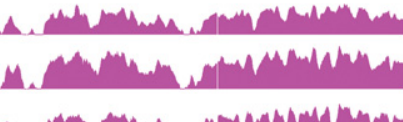

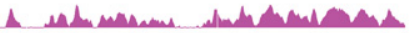
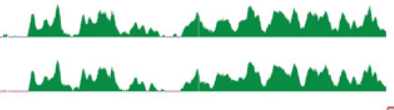

1.
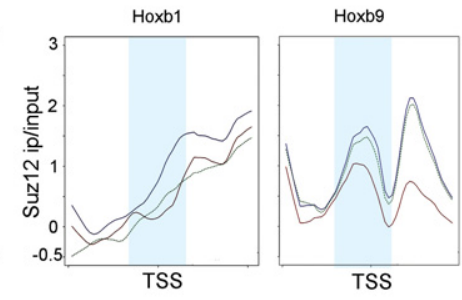

Figure 7. Gradual and progressive loss of repressive marks from the four mouse Hox clusters during RA-induced differentiation. (A) ChIP-on-chip analysis shows a gradual loss of the H3K27me3 repressive mark and SUZ12 occupancy over each Hox cluster upon RA treatment. Although many of the Hox genes are expressed early in the time course, over a whole cluster, $\mathrm{H} 3 \mathrm{~K} 27 \mathrm{me} 3$ is greatly reduced by $36 \mathrm{~h}$ of RA treatment. The gradual loss of repressive marks is observed from anterior to posterior genes in a Hox cluster over a time course correlating with colinearity. (B) Kinetics of reduction of SUZ12 occupancy over TSS of $\operatorname{Hox} A$ and $H o x B$ genes in paralogy groups 1 and 9 during RA-induced differentiation of ES cells. Anterior Hox genes rapidly lose SUZ12 over their TSS, as illustrated by changes for Hoxa1 and Hoxb1 at 2 h of RA treatment; whereas posterior genes show little change over their TSS in this time frame. The differences in the kinetics of loss of SUZ12 between genes correlates with their respective time of activation. A 500-bp region around the TSS is shown, and a 50-bp region around TSS is marked by a light blue band. The $y$-axis shows relative levels of occupancy of SUZ12.

Similarly, changes in the occupancy of SUZ12 on the TSS of Cyp26a1, Hobbit1, and Hotairm1 also correlate with their induction profiles (Supplemental Figs. S9, S10). Hence, in contrast to the H3K27me3 data, we found a strong correlation between the progressive and rapid removal of SUZ12 over the promoters of all of the Hox genes, ncRNAs (Hobbit1, Hotairm1), and Cyp26a1 and the timing of their activation (Fig. 7; Supplemental Figs. S9, S10). This implies that in this ES cell context, occupancy of SUZ12 is a better indicator of progressive changes in PcG-mediated repression than the H3K27me3 mark, which takes much longer to be removed. This further suggests that in general, the progressive removal of repressive marks, such as SUZ12 and H3K27me3, occurs first over TSS regions, whereas removal from the whole cluster is slower compared to the rate of gene activation.

With respect to active marks, there is evidence for the occupancy of Pol II over some genes in the $\operatorname{Hox} A, B$, and $D$ clusters in undifferentiated cells (Fig. 5; Supplemental Fig. S8). The polymerase is concentrated near the TSS and not located over the entire gene. This pattern is characteristic of paused Pol II, suggesting that polymerase has initiated but is waiting for signals to potentiate elongation. There is also a low level of H3K4me3 over the regions, consistent with the idea that this mark in mammalian cells frequently correlates with Pol II initiation at the promoter. In the case of Hoxa1, we have shown the gene is rapidly induced by RA through the recruitment of the Super Elongation Complex to the promoter, which stimulates elongation of the paused polymerase (Lin et al. 2011). In addition, we demonstrated that many of the most rapidly RAinduced genes in the ES cells are similarly regulated by transcriptional elongation and not by initiation (Lin et al. 2011). The co-occupancy of paused Pol II and $\mathrm{H} 3 \mathrm{~K} 4 \mathrm{me} 3$ has predictive value for future gene expression in ES cells and Drosophila (Gaertner et al. 2012). Hence, the presence of Pol II and H3K4me3 over Hox genes, such as Hoxa3, Hoxa5, and Hoxa13 suggests that they too may be induced by regulation of elongation of paused polymerases.

During the initial $24 \mathrm{~h}$ of differentiation, there is a progressive increase in occupancy of Pol II over genes. Consistent with the general colinear activation of Hox genes, this spreads from anterior to posterior genes in the HoxA and $H o x B$ clusters upon increased length of RA treatment (Fig. 5). There is a similar progressive increase in $\mathrm{H} 3 \mathrm{~K} 4 \mathrm{me} 3$. However, there are some unique features in the profiles observed over the HoxA and HoxB complexes that appear to correlate with ncRNA transcripts. At $4 \mathrm{~h}$ of RA treatment, Pol II is spread over a wider chromatin domain than expected if it is only present on the Hoxa1 and Hoxa2 gene body and promoter. The intergenic region also includes Hotairm 1 and Hotairm2. This suggests that Pol II is active on all of these transcriptional units at this early stage of induction, explaining the broad region of occupancy (Fig. 5; Supplemental Fig. S5). In HoxB, there is a rapid recruitment of $\mathrm{H} 3 \mathrm{~K} 4 \mathrm{me} 3$ and Pol II in the intergenic region between Hoxb4 and Hoxb5, which correlates with Hobbit1 transcription (Fig. 5; Supplemental Fig. S6).

The HoxC cluster shows little or no evidence of Pol II occupancy or change of H3K4me3 marks over this time course (Supplemental Fig. S8), which is consistent with the slow or delayed response of

\section{Genome Research}

www.genome.org 
genes in this cluster upon RA treatment (Fig. 1). In the HoxD cluster near TSS, we detect more bivalent marks over genes (H3K4me3 and $\mathrm{H} 3 \mathrm{~K} 27 \mathrm{me} 3)$. This may indicate that the HoxD cluster is ready for activation in later stages. Together, this analysis illustrates the diversity in epigenetic states between each of the Hox clusters and reveals that activation of ncRNAs has an impact in the epigenetic regulation of the Hox clusters.

\section{Heater and epigenetic changes}

Examining epigenetic changes flanking the Hox clusters, we focused on Heater. In Heater, there are four regions showing both H3K4me3 and H3K27me3 marks (bivalent state) and Pol II occupancy that correlate with the TSSs associated with transcription units in Heater (Fig. 6B). In uninduced cells, there is evidence for paused Pol II over the Heater transcribed region, indicating that some of these transcripts may also be regulated by transcriptional elongation in response to RA (Fig. 6). RA induces a rapid increase in occupancy of Pol II spread over the Heater region. Consistent with low levels of Heater transcription in ES cells, we detect occupancy of the elongation factors, AFF4 and ELL2, over the TSS2 region. Upon RA treatment, these factors along with CDK9, another elongation factor, increase their level of occupancy over the TSS2 transcription unit and are also rapidly recruited to TSS1 (Fig. 6B). This may underlie the rapid and synchronous response of Heater transcripts to RA, as shown for paused polymerase in other contexts (Chopra et al. 2009; Levine 2011; Lin et al. 2011; Lagha et al. 2013). The H-AR2 region flanking Heater also displays Pol II occupancy and bivalent H3K4me3 and H3K27me3 marks (Fig. 6). Upon RA treatment, there are dynamic changes in AFF4 and ELL2 occupancy. Hence, the H-AR2 region may also contribute to regulation of the Heater response to RA.

Together, these data further highlight the observation that the dynamics of binding of transcription factors and changes in epigenetic marks also correlate with expression of noncoding transcripts. This suggests they play roles in regulating noncoding regions within the Hox clusters in addition to the coding transcripts.

\section{Discussion}

In this study, we have analyzed the dynamic patterns of transcription in and around the four Hox clusters during the early stages of retinoid-induced differentiation of mouse ES cells into neuronal fates. Single RNA molecule fluorescence in situ hybridization approaches using probes for Cyp26a1 show that the majority of individual $\mathrm{KH} 2$ ES cells respond rapidly to RA in a relatively synchronous manner. The detailed time course revealed novel transcriptional and epigenetic changes. Among these findings, expression of ncRNAs in ES cells represents some of the most rapidly induced transcripts by RA and are associated with dynamic epigenetic changes observed over the Hox clusters. These noncoding transcripts are also expressed in mouse embryos and respond in vivo to RA treatment. Our data, showing the presence of adjacent RAREs and retinoid receptor occupancy, suggest that the Heater, Hobbit1, Hotairm1, and Hotairm2 noncoding regions are directly regulated by RA. In support of this idea, deletion of the DE-RARE in the endogenous $H o x B$ locus alters the expression and RA response of Hobbit1. These results on the dynamic nature of noncoding transcription in the Hox clusters raise the possibility they may have roles in shaping or potentiating epigenetic modification in these regions. This has important implications for understanding the complex and dynamic regulation of Hox clusters in differentiation and development.

With respect to Hox coding regions, in general, there is a colinear order in the activation of gene expression during RAinduced differentiation. However, surprisingly, our analyses uncovered several cases in which genes display a lack of strict temporal colinearity based on steady-state levels of expression. This is clearly observed for the Group 5 genes in the HoxA and HoxB clusters, which are expressed earlier than their respective Group 3 genes (Figs. 1, 3). This disparity in timing does not account for possible differences in parameters, such as RNA stability or transcriptional efficiency of promoters. Epigenetic changes are associated with noncolinear gene activation and include rapid loss of SUZ12 over the TSS and gain of H3K4me3 and elongating Pol II. Hence, it will be interesting to explore the mechanisms associated with these apparent alterations in colinearity.

The analyses of Hox gene promoter regions during RA-induced differentiation reveals that diverse mechanisms appear to function in potentiating their response. Some of the fastest responding genes, Hoxa1 and Hoxa5, are induced by modulating the elongation of paused polymerase, whereas others, Hoxb1, Hoxb4, and Hoxb5 display rapid recruitment of Pol II (Fig. 5; Supplemental Fig. S3; Lin et al. 2011). These Hox genes displaying a rapid RA response have RAREs associated with their loci. This suggests that induction using paused polymerase and rapid recruitment of Pol II to promoters is achieved in part through integrating direct transcriptional inputs of retinoid signaling.

The mechanisms for regulation by retinoids and other nuclear hormone receptors are themselves diverse and involve the processes of both activation and/or repression to modulate the recruitment and activity of Pol II (Kininis and Kraus 2008; Evans and Mangelsdorf 2014).

Furthermore, in the presence of ligand, there is often a dramatic genome-wide reorganization in receptor occupancy associated with their regulatory roles in cell type-specific gene expression involving loss from preexisting sites, recruitment to new locations, and altered affinities for coactivators and corepressors (Kininis et al. 2009; Mahony et al. 2011; Uhlenhaut et al. 2013). Consistent with this, our analysis has shown that there are dynamic changes in the occupancy profiles of RARs (A, B, and $\mathrm{G}$ ) over the HoxA and HoxB clusters. These receptors are bound to the Hoxa1-Hoxa3 region in uninduced ES cells and rapidly lost by $2 \mathrm{~h}$ of RA treatment (Fig. 5). In contrast, RARA is rapidly recruited to the Hoxb4-Hoxb5 intergenic region by $2 \mathrm{~h}$ of RA treatment. Hoxb1 shows constitutive binding of RARA, RARB, and RARG irrespective of RA treatment. This illustrates that multiple mechanisms are implicated in coordinating the temporal regulation of Hox genes in response to RA.

Paused polymerase, rapid recruitment of Pol II, and dynamic changes in RAR occupancy also play roles in regulating transcripts from the Heater, Hotairm1, and Hobbit1 noncoding regions in a manner similar to the regulation of Hox coding regions. There is evidence of paused Pol II over some TSS of Heater, as in uninduced cells; there is preloading of Pol II, AFF4, and ELL2 that rapidly increases their occupancy upon RA treatment (Fig. 6). There is also an increase in CDK9 occupancy upon RA treatment, consistent with a role for control of elongation in modulating transcription in this noncoding region. The Heater Associated Regions (H-AR1/ 2) display extensive occupancy of retinoic acid receptors (RXRA, RARA, RARB, and RARG) and contain a number of RARE Direct Repeat motifs (Fig. 6; Supplemental Fig. S7). Hence, the extremely rapid response of Heater to RA appears to be mediated by a 
combination of paused polymerase and direct inputs from retinoid signaling in a manner analogous to Hoxa $150 \mathrm{~kb}$ downstream. The Heater, Hotairm1, Hotairm2, and Hobbit1 regions are all associated RAREs that may be involved in mediating their rapid response. Hobbit1 is positioned in the intergenic region between Hoxb4 and Hoxb5, flanked by the $D E$ - and B4U-RAREs. Our analysis shows the DE-RARE is required for the response of Hobbit1 to RA in mouse embryos (Supplemental Fig. S6). This illustrates a case in which the regulation of coding (Ahn et al. 2014) and ncRNAs in Hox clusters is mediated by a shared RARE-dependent enhancer.

We have focused on understanding regulation of these ncRNAs, but it is worth noting that functionally three transcripts (Halr1; isoforms 1-3) located in the Heater region have been implicated in regulation of Hoxa1. Knockdown of these Halr1RNAs leads to increased Hoxa1 levels in uninduced ES cells, and RA treatment alters this relationship (Maamar et al. 2013). The Heater region has a very complex pattern of transcription, as we have characterized at least eight spliced variants generated from three different TSS on both strands. In addition, there are multiple unspliced transcripts induced from a separate TSS (Fig. 4). Therefore, changes in the expression levels and splice variants of different transcripts induced by RA from the Heater region may be responsible for uncoupling of Halr1expression and Hoxa1 regulation.

Several previous studies have characterized epigenetic events, both genome-wide and Hox cluster-specific, associated with RA-induced differentiation of mouse and human ES cells (Boyer et al. 2005, 2006; Bernstein et al. 2006; Kashyap et al. 2011; Mahony et al. 2011; Gaertner et al. 2012; Mazzoni et al. 2013; Sheikh et al. 2014). Nearly all of these have focused on events after $24 \mathrm{~h}$ of RA treatment or use RA in combination with longer (3-8 d) embryoid body differentiation protocols. In this study, we characterized the early dynamic epigenetic events ( $0-24 \mathrm{~h})$ associated with expression of both coding and ncRNAs in and around the Hox clusters. Previous studies have documented the loss of H3K27me3 from Hox clusters between 24 and $96 \mathrm{~h}$ of differentiation, leading to the assumption that removal of this repressive mark is an early event needed for activation of Hox genes.

Indeed, over the initial $24 \mathrm{~h}$ period, we observe a progressive decrease in the levels of H3K27me3 over the most 3' genes, Hoxa1 and Hoxb1 (Figs. 5, 7). However, surprisingly the rate of removal of H3K27me3 over all four Hox complexes is slow compared with the activation of coding and noncoding transcripts or the appearance of the activation marks (H3K4me3) and Pol II occupancy. The occupancy of the SUZ12, a component of the PRC2 complex, shows a similar slow rate of removal over all four Hox clusters. However, examining the TSS regions of Hox genes, ncRNAs (Hobbit1 and Hotairm1) and Cyp26a1, indicates that there is a temporal correlation in the removal of SUZ12 from TSS and the respective timing of gene expression. Rapid removal occurs first over $3^{\prime}$ genes, such as Hoxa 1 and Hoxb1, and progressively is removed from more $5^{\prime}$ genes at later time points (Fig. 7; Supplemental Fig. S10). This indicates that in general, the progressive removal of repressive marks such as SUZ12 and H3K27me3 occurs first over TSS regions, whereas removal from the whole cluster is slower compared to the rate of gene activation. Similar findings with Cyp26a1 (Supplemental Fig. S9) indicate that this observation is not restricted to Hox clusters. This raises the possibility that removal of SUZ12 at promoters might be done through active participation of MLLs and demethylases, whereas over the whole cluster, these marks are removed by patterning signals or passively during transcription and subsequent cell division. Our findings imply that in this ES cell context, occupancy of SUZ12 is a better indicator of progressive changes in
Polycomb-mediated repression than the H3K27me3 mark, which takes much longer to be removed.

We find that rapid induction of noncoding transcripts and reorganization of domains of retinoid receptor occupancy impact the epigenetic state of chromatin in Hox clusters. For example, the Hoxb4-Hoxb5 intergenic region containing Hobbit1 shows a dramatic gain of H3K $4 \mathrm{me} 3$ after $4 \mathrm{~h}$ of RA treatment along with the recruitment of RARA and Pol II. In the case of Hotairm1, there are low levels of H3K27me3 in uninduced ES cells compared to the adjacent Hoxa1 and Hoxa2 genes that rapidly declines upon RA treatment (Supplemental Fig. S5A). It is embedded in a region spanning Hoxa1-Hoxa3 that displays broad occupancy of retinoid receptors and paused polymerase in uninduced cells. In the Heater region, there is paused Pol II and co-occupancy of H3K4me3 and H3K27me3 marks on multiple TSS in uninduced ES cells (Fig. 6). These bivalent states persist upon RA induction. This shows that the bivalent state can be associated with synchronous and rapid induction of noncoding transcripts in differentiating ES cells.

These analyses of early events associated with RA-induced differentiation illustrate the interplay between RARE cis-regulatory elements, rapidly induced noncoding transcripts from both strands, and dynamic epigenetics changes in shaping the overall expression profile and epigenetic state in an around Hox clusters.

\section{Methods}

\section{RNA isolation}

RNA isolation was performed using TRIzol (Life Technologies) and later purified by the RNeasy Kit (Qiagen). RNA was tested for integrity and concentration using the RNA 6000 Nano Assay and RNA LabChips on the Agilent Bioanalyzer 2100 (Agilent Technologies).

\section{Affymetrix microarray analysis}

Two hundred nanograms total RNA was labeled, and cRNA targets were generated from total RNA samples using the MessageAmp III RNA Amplification Kit (Applied Biosystems/Ambion), according to the corresponding instruction manual. Biotinylated and fragmented cRNA targets $(15 \mu \mathrm{g})$ were hybridized to Affymetrix Mouse Genome 4302.0 arrays using the GeneChip Fluidics Station 450 according to the manufacturer's standard protocol. Arrays were scanned with a GeneChip Scanner 3000 7G, and the image data on each individual microarray chip were scaled to 150 target intensity, using the GeneChip Command Console Software (AGCC software v.1.1) (Affymetrix). Microarray data were analyzed in R (2.11.1) (R Core Team 2015) (http://www.Rproject.org/) using the affy (1.26.1) (Gautier et al. 2004) and limma 3.4.3 (Smyth 2005) packages. Normalization was done using rma. Annotation information was taken from Bioconductor annotation package mouse4302.db (2.4.1). $k$-means clustering was done in $R$ (2.13.2) with $k=9$.

\section{Agilent tiling microarrays}

Total RNA ( $1 \mu \mathrm{g})$ was amplified according to Ambion's Message Amp II aRNA Amplification Kit (AM1751). Agilent's One Color RNA Spike-In Kit was used as a positive control RNA. Amplified mRNA (aRNA) $(2 \mu \mathrm{g})$ was labeled with cy3 dye and hybridized to custom Agilent 2x105K Hox tiling arrays (details in Supplemental Data) according to the manufacturer's instruction. Agilent tiling arrays were hybridized in a single-color configuration. Agilent "gMeanSignal" was used as the measurement for each spot. Data were analyzed using the limma package (Smyth 2005) and normalized between arrays using scale normalization. Replicates were

\section{Genome Research}

www.genome.org 
averaged and bedGraph files were created and visualized using IGV (Thorvaldsdottir et al. 2013) and the UCSC Genome Browser (Kent et al. 2002).

\section{RNA-seq}

Libraries were prepared using the Small RNA Sample Prep Kit (Illumina, FC-102-1010) with 10× v1.5 sRNA 3' Adaptor (Illumina, 15000263) and mRNA-seq Library Prep Kit (Illumina, RS-1000801) according to the manufacturer's protocol (15018460 Rev A Oct 10) (details in Supplemental Data) and sequenced.

\section{ChIP-on-chip}

ChIP was done according to the Upstate protocol (Smith et al. 2010). Input DNA and IP DNA (10 ng) were amplified and labeled according to the Agilent Genomic DNA Labeling Kit PLUS (G448190010). Custom Agilent $2 \times 105 \mathrm{~K}$ Hox tiling arrays were hybridized with a mixture of $4 \mu \mathrm{g}$ Cy3 labeled DNA and $4 \mu \mathrm{g}$ Cy5 labeled DNA probes. Hybridizations were performed for $24 \mathrm{~h}$ at $65^{\circ} \mathrm{C}$ under standard conditions. Microarray images were acquired with an Agilent High-Resolution DNA Microarray Scanner (G2505C). For image analysis, Agilent Feature Extraction software (Version 10.5.1.1) was used. Agilent tiling arrays were hybridized in a twocolor configuration. Data were analyzed using the limma (3.4.3) package and normalized within arrays using loess normalization.

\section{Quantitative PCR of Hox genes using TLDA cards}

Quantative PCR was done using TLDA cards as described in Supplemental Methods. Analysis of the fluorescence curves was done using ABI's SDS2.3 software. All curves that showed errors as determined by the SDS2.3 software or that were above $35 \mathrm{Ct}$ were thrown out. The remaining Ct values were exported and analyzed using DataAssist v2.0. Gapdh and Tbp were used as endogenous controls.

\section{Quantitative PCR of noncoding transcripts using SYBR green assays}

For ES cell and mouse embryo RNA, $5 \mu \mathrm{g}$ total RNA was used as a template in $20 \mu \mathrm{L}$ total volume reaction of the SuperScript II (Invitrogen) reverse transcription kit using oligo dT primers. The $20-\mu \mathrm{L}$ reaction was diluted 50 times, and $2 \mu \mathrm{L}$ were used for qPCR and cycled on an ABI 7900HT according to ABI's standard protocol. Analysis of the fluorescence curves was done using ABI's SDS2.4 software. All curves that showed errors as determined by the SDS2.4 software or that were above $35 \mathrm{Ct}$ were thrown out. The remaining Ct values were exported and analyzed using the Biogazelle qBase plus version 2.4 software to generate normalized relative quantities. Gapdh and ATP5b were used as endogenous controls. Each primer pair was standardized for a linear range of amplification through standard curve analysis. Analyses of the fluorescence curves was done using ABI's SDS2.4 software. All curves that showed errors as determined by the SDS2.4 software or that were above $35 \mathrm{Ct}$ were thrown out. Analyses were done as discussed in the previous section.

\section{RA treatment of mouse embryos}

Wild-type pregnant female CD-1 mice (10.0 dpc) and mice carrying the $D E-R A R E$ mutant alleles $(\triangle D E)(11.5 \mathrm{dpc})$ were orally injected (gavage) with all-trans retinoic acid dissolved in $160 \mu \mathrm{L}$ of mineral oil to deliver a dose of $20 \mu \mathrm{g}$ RA/g body weight. After 8 $\mathrm{h}$, embryos were harvested and RNA was isolated. Total RNA (5 $\mu \mathrm{g}$ ) was used as template in $50 \mu \mathrm{L}$ total volume reaction of SuperScript II (Invitrogen) reverse transcription kit using oligo
dT primers. Total RNA was isolated from whole embryos or pools of 3-5 dissected neural tubes and analyzed on an ABI 7900HT according to the standard protocol.

\section{Stellaris and HCR fluorescence in situ hybridization}

Stellaris and HCR fluorescence in situ hybridization was done according to the manufacturer's protocol with minor modifications (details in Supplemental Methods). ES colonies were immobilized on 35-mm imaging grade plastic ibiTreat dishes (Ibidi Biosciences). Images were acquired with a Perkin-Elmer Ultraview spinning disc microscope with a CSU-X1 Yokogawa disc, equipped with a C9100 Hamamatsu Photonics EM-CCD. A 100× 1.4 NA Plan-apochromatic objective was used. The 405-nm, 561-nm, and 640-nm laser lines were used to excite DAPI, Quasar 570, and Quasar 670, respectively. Quasar 670 emission was collected through a 455-505 nm, 660-750 nm dual band pass filter, whereas Quasar 570 and DAPI were both collected with a 415-475 $\mathrm{nm}, 580-650 \mathrm{~nm}$ dual band pass filter.

\section{Data access}

The raw and processed data from this study have been submitted to the NCBI Gene Expression Omnibus (GEO; http://www.ncbi.nlm. nih.gov/geo/) under series accession number GSE61590. All novel noncoding transcripts and isoforms described in this study have been assigned MGI-approved marker names with GenBank accession numbers as listed in Supplemental Table S7. All original source data for unprocessed microscope images and raw qPCR data have been deposited in the Stowers Institute Original Data Repository and are available online at http://odr.stowers.org/ websimr/.

\section{Acknowledgments}

We thank Julia Zeitlinger, Marco Blanchette, and Ron Conaway for advice and guidance on the experiments and their design; Tari Parmely and members of the Stowers Institute Tissue Culture Facility for assistance with mouse ES cells and other cell culture needs; the Stowers Institute Molecular Biology Facility for microarray and sequencing approaches; Brian Sanderson for help with qPCR analysis; and members of the Krumlauf laboratory for valuable discussions and feedback. All experiments involving mice were approved by the Institutional Animal Care and Use Committee of the Stowers Institute for Medical Research (Krumlauf Protocol 2013-0114). This work was performed to fulfill, in part, requirements for B.D.K.'s PhD thesis research as a student registered with the Open University. This research was supported by funds from the Stowers Institute and also by funds provided by the Alex's Lemonade Stand Foundation for Childhood Cancer and a grant from the National Institutes of Health (R01CA150265) to A.S.

\section{References}

Ahn Y, Mullan HE, Krumlauf R. 2014. Long-range regulation by shared retinoic acid response elements modulates dynamic expression of posterior Hoxb genes in CNS development. Dev Biol 388: 134-144.

Alexander T, Nolte C, Krumlauf R. 2009. Hox genes and segmentation of the hindbrain and axial skeleton. Annu Rev Cell Dev Biol 25: 431-456.

Beard C, Hochedlinger K, Plath K, Wutz A, Jaenisch R. 2006. Efficient method to generate single-copy transgenic mice by site-specific integration in embryonic stem cells. Genesis 44: 23-28.

Begemann G, Schilling TF, Rauch GJ, Geisler R, Ingham PW. 2001. The zebrafish neckless mutation reveals a requirement for raldh2 in mesodermal signals that pattern the hindbrain. Development 128: 3081-3094.

Bel-Vialar S, Itasaki N, Krumlauf R. 2002. Initiating Hox gene expression: In the early chick neural tube differential sensitivity to FGF and RA 
signaling subdivides the HoxB genes in two distinct groups. Development 129: 5103-5115.

Bernstein BE, Mikkelsen TS, Xie X, Kamal M, Huebert DJ, Cuff J, Fry B, Meissner A, Wernig M, Plath K, et al. 2006. A bivalent chromatin structure marks key developmental genes in embryonic stem cells. Cell 125: 315-326.

Boyer LA, Lee TI, Cole MF, Johnstone SE, Levine SS, Zucker JP, Guenther MG, Kumar RM, Murray HL, Jenner RG, et al. 2005. Core transcriptional regulatory circuitry in human embryonic stem cells. Cell 122: 947-956.

Boyer LA, Plath K, Zeitlinger J, Brambrink T, Medeiros LA, Lee TI, Levine SS Wernig M, Tajonar A, Ray MK, et al. 2006. Polycomb complexes repress developmental regulators in murine embryonic stem cells. Nature 441: 349-353.

Chambeyron S, Bickmore WA. 2004. Chromatin decondensation and nuclear reorganization of the HoxB locus upon induction of transcription. Genes Dev 18: 1119-1130.

Chambon P. 1994. The retinoid signaling pathway; molecular and genetic analysis. Semin Cell Biol 5: 115-125.

Choi HM, Chang JY, Trinh le A, Padilla JE, Fraser SE, Pierce NA. 2010. Programmable in situ amplification for multiplexed imaging of mRNA expression. Nat Biotechnol 28: 1208-1212.

Choi HM, Beck VA, Pierce NA. 2014. Next-generation in situ hybridization chain reaction: higher gain, lower cost, greater durability. ACS Nano 8: 4284-4294.

Chopra VS, Hong JW, Levine M. 2009. Regulation of Hox gene activity by transcriptional elongation in Drosophila. Curr Biol 19: 688-693.

Conlon RA, Rossant J. 1992. Exogenous retinoic acid rapidly induces anterior ectopic expression of murine Hox-2 genes in vivo. Development 116: 357-368.

de Rosa R, Grenier JK, Andreeva T, Cook CE, Adoutte A, Akam M, Carroll SB, Balavoine G. 1999. Hox genes in brachiopods and priapulids and protostome evolution. Nature 399: 772-776.

Deschamps J, van Nes J. 2005. Developmental regulation of the Hox genes during axial morphogenesis in the mouse. Development 132: 29312942.

Diez del Corral R, Storey KG. 2004. Opposing FGF and retinoid pathways: a signalling switch that controls differentiation and patterning onset in the extending vertebrate body axis. Bioessays 26: 857-869.

Diez del Corral R, Olivera-Martinez I, Goriely A, Gale E, Maden M, Storey K. 2003. Opposing FGF and retinoid pathways control ventral neural pattern, neuronal differentiation, and segmentation during body axis extension. Neuron 40: 65-79.

Drab M, Haller H, Bychkov R, Erdmann B, Lindschau C, Haase H, Morano I, Luft FC, Wobus AM. 1997. From totipotent embryonic stem cells to spontaneously contracting smooth muscle cells: a retinoic acid and db-cAMP in vitro differentiation model. FASEB J 11: 905-915.

Duboule D, Dollé P. 1989. The structural and functional organization of the murine HOX gene family resembles that of Drosophila homeotic genes. EMBO J 8: 1497-1505.

Dupé V, Davenne M, Brocard J, Dollé P, Mark M, Dierich A, Chambon P, Rijli F. 1997. In vivo functional analysis of the Hoxa1 3' retinoid response element (3' RARE). Development 124: 399-410.

Evans RM, Mangelsdorf DJ. 2014. Nuclear receptors, RXR, and the Big Bang. Cell 157: 255-266.

Femino AM, Fay FS, Fogarty K, Singer RH. 1998. Visualization of single RNA transcripts in situ. Science 280: $585-590$.

Fraichard A, Chassande O, Bilbaut G, Dehay C, Savatier P, Samarut J. 1995 In vitro differentiation of embryonic stem cells into glial cells and functional neurons. J Cell Sci 108 (Pt 10): 3181-3188.

Gaertner B, Johnston J, Chen K, Wallaschek N, Paulson A, Garruss AS, Gaudenz K, De Kumar B, Krumlauf R, Zeitlinger J. 2012. Poised RNA polymerase II changes over developmental time and prepares genes for future expression. Cell Rep 2: 1670-1683.

Gale E, Zile M, Maden M. 1999. Hindbrain respecification in the retinoiddeficient quail. Mech Dev 89: 43-54.

Gautier L, Cope L, Bolstad BM, Irizarry RA. 2004. affy-analysis of Affymetrix GeneChip data at the probe level. Bioinformatics 20: 307-315.

Gavalas A. 2002. ArRAnging the hindbrain. Trends Neurosci 25: 61-64.

Gavalas A, Krumlauf R. 2000. Retinoid signalling and hindbrain patterning. Curr Opin Genet Dev 10: 380-386.

Gillespie RF, Gudas LJ. 2007. Retinoic acid receptor isotype specificity in F9 teratocarcinoma stem cells results from the differential recruitment of coregulators to retinoic response elements. J Biol Chem 282: 33421 33434.

Glaser T, Brustle O. 2005. Retinoic acid induction of ES-cell-derived neurons: the radial glia connection. Trends Neurosci 28: 397-400.

Gottlieb DI, Huettner JE. 1999. An in vitro pathway from embryonic stem cells to neurons and glia. Cells Tissues Organs 165: 165-172.

Gould A, Morrison A, Sproat G, White RA, Krumlauf R. 1997. Positive crossregulation and enhancer sharing: two mechanisms for specifying overlapping Hox expression patterns. Genes Dev 11: 900-913.
Gould A, Itasaki N, Krumlauf R. 1998. Initiation of rhombomeric Hoxb4 expression requires induction by somites and a retinoid pathway. Neuron 21: $39-51$.

Graham A, Papalopulu N, Krumlauf R. 1989. The murine and Drosophila homeobox gene complexes have common features of organization and expression. Cell 57: 367-378.

Grandel H, Lun K, Rauch GJ, Rhinn M, Piotrowski T, Houart C, Sordino P, Küchler AM, Schulte-Merker S, Geisler R, et al. 2002. Retinoic acid signalling in the zebrafish embryo is necessary during pre-segmentation stages to pattern the anterior-posterior axis of the CNS and to induce a pectoral fin bud. Development 129: 2851-2865.

Gross D, McGinnis W. 1996. DEAF-1, a novel protein that binds an essential region in a Deformed response element. EMBO J 15: 1961-1970.

Guttman M, Garber M, Levin JZ, Donaghey J, Robinson J, Adiconis X, Fan L, Koziol MJ, Gnirke A, Nusbaum C, et al. 2010. Ab initio reconstruction of cell type-specific transcriptomes in mouse reveals the conserved multiexonic structure of lincRNAs. Nat Biotechnol 28: 503-510.

Hernandez RE, Putzke AP, Myers JP, Margaretha L, Moens CB. 2007. Cyp26 enzymes generate the retinoic acid response pattern necessary for hindbrain development. Development 134: 177-187.

Horton C, Maden M. 1995. Endogenous distribution of retinoids during normal development and teratogenesis in the mouse embryo. Dev Dyn 202: 312-323.

Houle M, Prinos P, Iulianella A, Bouchard N, Lohnes D. 2000. Retinoic acid regulation of $\mathrm{Cdx} 1$ : an indirect mechanism for retinoids and vertebral specification. Mol Cell Biol 20: 6579-6586.

Houle M, Sylvestre JR, Lohnes D. 2003. Retinoic acid regulates a subset of Cdx1 function in vivo. Development 130: 6555-6567.

Ikuta T, Yoshida N, Satoh N, Saiga H. 2004. Ciona intestinalis Hox gene cluster: its dispersed structure and residual colinear expression in development. Proc Natl Acad Sci 101: 15118-15123.

Isaacs H, Pownall M, Slack J. 1998. Regulation of Hox gene expression and posterior development by the Xenopus caudal homolog Xcad3. EMBO I 17: 3413-3427.

Itasaki N, Sharpe J, Morrison A, Krumlauf R. 1996. Reprogramming Hox expression in the vertebrate hindbrain: influence of paraxial mesoderm and rhombomere transposition. Neuron 16: 487-500.

Kashyap V, Gudas LJ, Brenet F, Funk P, Viale A, Scandura JM. 2011. Epigenomic reorganization of the clustered Hox genes in embryonic stem cells induced by retinoic acid. I Biol Chem 286: 3250-3260.

Kawaguchi J, Mee PJ, Smith AG. 2005. Osteogenic and chondrogenic differentiation of embryonic stem cells in response to specific growth factors. Bone 36: 758-769.

Kent WJ, Sugnet CW, Furey TS, Roskin KM, Pringle TH, Zahler AM, Haussler D. 2002. The human genome browser at UCSC. Genome Res 12: 996-1006.

Kininis M, Kraus WL. 2008. A global view of transcriptional regulation by nuclear receptors: gene expression, factor localization, and DNA sequence analysis. Nucl Recept Signal 6: e005.

Kininis M, Isaacs GD, Core LJ, Hah N, Kraus WL. 2009. Postrecruitment regulation of RNA polymerase II directs rapid signaling responses at the promoters of estrogen target genes. Mol Cell Biol 29: 1123-1133.

Kmita M, Duboule D. 2003. Organizing axes in time and space; 25 years of colinear tinkering. Science 301: 331-333.

Lagha M, Bothma JP, Esposito E, Ng S, Stefanik L, Tsui C, Johnston J, Chen K, Gilmour DS, Zeitlinger J, et al. 2013. Paused Pol II coordinates tissue morphogenesis in the Drosophila embryo. Cell 153: 976-987.

Langston AW, Gudas LJ. 1992. Identification of a retinoic acid responsive enhancer $3^{\prime}$ of the murine homeobox gene Hox-1.6. Mech Dev 38: 217-228.

Lee TI, Jenner RG, Boyer LA, Guenther MG, Levine SS, Kumar RM, Chevalier B, Johnstone SE, Cole MF, Isono K, et al. 2006. Control of developmental regulators by Polycomb in human embryonic stem cells. Cell 125: 301-313.

Levine M. 2011. Paused RNA polymerase II as a developmental checkpoint. Cell 145: 502-511.

Lewis EB. 1978. A gene complex controlling segmentation in Drosophila. Nature 276: $565-570$.

Lin C, Garrett AS, De Kumar B, Smith ER, Gogol M, Seidel C, Krumlauf R, Shilatifard A. 2011. Dynamic transcriptional events in embryonic stem cells mediated by the super elongation complex (SEC). Genes Dev 25: $1486-1498$.

Linville A, Gumusaneli E, Chandraratna RA, Schilling TF. 2004. Independent roles for retinoic acid in segmentation and neuronal differentiation in the zebrafish hindbrain. Dev Biol 270: 186-199.

Lohnes D. 2003. The Cdx1 homeodomain protein: an integrator of posterior signaling in the mouse. Bioessays 25: 971-980.

Lowe CJ, Wu M, Salic A, Evans L, Lander E, Stange-Thomann N, Gruber CE, Gerhart J, Kirschner M. 2003. Anteroposterior patterning in hemichordates and the origins of the chordate nervous system. Cell 113: 853-865. 
Maamar H, Cabili MN, Rinn J, Raj A. 2013. linc-HOXA1 is a noncoding RNA that represses Hoxa1 transcription in cis. Genes Dev 27: 1260-1271.

Maden M. 2002. Retinoid signalling in the development of the central nervous system. Nat Rev Neurosci 3: 843-853.

Mahony S, Mazzoni EO, McCuine S, Young RA, Wichterle H, Gifford DK. 2011. Ligand-dependent dynamics of retinoic acid receptor binding during early neurogenesis. Genome Biol 12: R2.

Mallo M, Wellik DM, Deschamps J. 2010. Hox genes and regional patterning of the vertebrate body plan. Dev Biol 344: 7-15.

Manzanares M, Wada H, Itasaki N, Trainor PA, Krumlauf R, Holland PW. 2000. Conservation and elaboration of Hox gene regulation during evolution of the vertebrate head. Nature 408: 854-857.

Marshall H, Nonchev S, Sham MH, Muchamore I, Lumsden A, Krumlauf R. 1992. Retinoic acid alters hindbrain Hox code and induces transformation of rhombomeres 2/3 into a 4/5 identity. Nature 360: 737-741.

Marshall H, Studer M, Pöpperl H, Aparicio S, Kuroiwa A, Brenner S, Krumlauf R. 1994. A conserved retinoic acid response element required for early expression of the homeobox gene Hoxb-1. Nature 370: $567-571$

Mazzoni EO, Mahony S, Peljto M, Patel T, Thornton SR, McCuine S, Reeder C, Boyer LA, Young RA, Gifford DK, et al. 2013. Saltatory remodeling of Hox chromatin in response to rostrocaudal patterning signals. Nat Neurosci 16: 1191-1198.

McGinnis W, Krumlauf R. 1992. Homeobox genes and axial patterning. Cell 68: $283-302$.

Molotkova N, Molotkov A, Sirbu IO, Duester G. 2005. Requirement of mesodermal retinoic acid generated by Raldh 2 for posterior neural transformation. Mech Dev 122: 145-155.

Moroni M, Vigano M, Mavilio F. 1993. Regulation of the human HOXD4 gene by retinoids. Mech Dev 44: 139-154.

Niederreither K, Subbarayan V, Dollé P, Chambon P. 1999. Embryonic retinoic acid synthesis is essential for early mouse post-implantation development. Nat Genet 21: 444-448.

Niederreither K, Vermot J, Schuhbaur B, Chambon P, Dollé P. 2000. Retinoic acid synthesis and hindbrain patterning in the mouse embryo. Development 127: 75-85.

Ogura T, Evans RM. 1995a. Evidence for two distinct retinoic acid response pathways for Hoxb-1 gene regulation. Proc Natl Acad Sci 92: 392-396.

Ogura T, Evans RM. 1995b. A retinoic acid-triggered cascade of $H O X B 1$ gene activation. Proc Natl Acad Sci 92: 387-391.

Oosterveen T, Niederreither K, Dollé P, Chambon P, Meijlink F, Deschamps J. 2003. Retinoids regulate the anterior expression boundaries of $5^{\prime}$ Hoxb genes in posterior hindbrain. EMBO J 22: 262-269.

Oosterveen T, Meijlink F, Deschamps J. 2004. Expression of retinaldehyde dehydrogenase II and sequential activation of $5^{\prime}$ Hoxb genes in the mouse caudal hindbrain. Gene Expr Patterns 4: 243-247.

Packer AI, Crotty DA, Elwell VA, Wolgemuth DJ. 1998. Expression of the murine Hoxa4 gene requires both autoregulation and a conserved retinoic acid response element. Development 125: 1991-1998.

Pani AM, Mullarkey EE, Aronowicz J, Assimacopoulos S, Grove EA, Lowe CJ. 2012. Ancient deuterostome origins of vertebrate brain signalling centres. Nature 483: 289-294.

Papalopulu N, Lovell-Badge R, Krumlauf R. 1991. The expression of murine Hox-2 genes is dependent on the differentiation pathway and displays a collinear sensitivity to retinoic acid in F9 cells and Xenopus embryos. Nucleic Acids Res 19: 5497-5506.

Pownall ME, Isaacs HV, Slack JM. 1998. Two phases of Hox gene regulation during early Xenopus development. Curr Biol 8: 673-676.

R Core Team. 2015. R: a language and environment for statistical computing. R Foundation for Statistical Computing, Vienna, cAustria. http://www. R-project.org/.

Raj A, Tyagi S. 2010. Detection of individual endogenous RNA transcripts in situ using multiple singly labeled probes. Methods Enzymol 472: 365-386.

Rhinn M, Dollé P. 2012. Retinoic acid signalling during development. Development 139: 843-858.

Rosenbloom KR, Sloan CA, Malladi VS, Dreszer TR, Learned K, Kirkup VM, Wong MC, Maddren M, Fang R, Heitner SG, et al. 2013. ENCODE data in the UCSC Genome Browser: year 5 update. Nucleic Acids Res 41(Database issue): D56-D63.

Sandelin A, Wasserman WW. 2005. Prediction of nuclear hormone receptor response elements. Mol Endocrinol 19: 595-606.

Scott WJ Jr, Walter R, Tzimas G, Sass JO, Nau H, Collins MD. 1994. Endogenous status of retinoids and their cytosolic binding proteins in limb buds of chick vs mouse embryos. Dev Biol 165: 397-409.

Seo HC, Edvardsen RB, Maeland AD, Bjordal M, Jensen MF, Hansen A, Flaat M, Weissenbach J, Lehrach H, Wincker P, et al. 2004. Hox cluster disintegration with persistent anteroposterior order of expression in Oikopleura dioica. Nature 431: 67-71.
Serpente P, Tümpel S, Ghyselinck NB, Niederreither K, Wiedemann LM, Dollé P, Chambon P, Krumlauf R, Gould AP. 2005. Direct crossregulation between retinoic acid receptor $\beta$ and Hox genes during hindbrain segmentation. Development 132: 503-513.

Sharpe J, Nonchev S, Gould A, Whiting J, Krumlauf R. 1998. Selectivity, sharing and competitive interactions in the regulation of Hoxb genes. EMBO J 17: 1788-1798.

Sheikh BN, Downer NL, Kueh AJ, Thomas T, Voss AK. 2014. Excessive versus physiologically relevant levels of retinoic acid in embryonic stem cell differentiation. Stem Cells 32: 1451-1458.

Simeone A, Acampora D, Arcioni L, Andrews PW, Boncinelli E, Mavilio F. 1990. Sequential activation of HOX2 homeobox genes by retinoic acid in human embryonal carcinoma cells. Nature 346: 763-766.

Simeone A, Acampora D, Nigro V, Faiella A, D’Esposito M, Stornaiuolo A, Mavilio F, Boncinelli E. 1991. Differential regulation by retinoic acid of the homeobox genes of the four $\mathrm{HOX}$ loci in human embryonal carcinoma cells. Mech Dev 33: 215-227.

Sirbu IO, Gresh L, Barra J, Duester G. 2005. Shifting boundaries of retinoic acid activity control hindbrain segmental gene expression. Development 132: 2611-2622.

Smith KT, Martin-Brown SA, Florens L, Washburn MP, Workman JL. 2010. Deacetylase inhibitors dissociate the histone-targeting ING2 subunit from the Sin3 complex. Chem Biol 17: 65-74.

Smyth GK. 2005. limma: linear models for microarray data. In Bioinformatics and computational biology solutions using $R$ and bioconductor (ed. Gentleman R, et al.), pp. 397-420. Springer, New York.

Soshnikova N, Duboule D. 2008. Epigenetic regulation of Hox gene activation: the waltz of methyls. Bioessays 30: 199-202.

Studer M, Popperl H, Marshall H, Kuroiwa A, Krumlauf R. 1994. Role of a conserved retinoic acid response element in rhombomere restriction of Hoxb-1. Science 265: 1728-1732.

Studer M, Gavalas A, Marshall H, Ariza-McNaughton L, Rijli FM, Chambon P, Krumlauf R. 1998. Genetic interactions between Hoxa1 and Hoxb1 reveal new roles in regulation of early hindbrain patterning. Development 125: $1025-1036$.

Thorvaldsdottir H, Robinson JT, Mesirov JP. 2013. Integrative Genomics Viewer (IGV): high-performance genomics data visualization and exploration. Brief Bioinform 14: 178-192.

Tümpel S, Wiedemann LM, Krumlauf R. 2009. Hox genes and segmentation of the vertebrate hindbrain. Curr Top Dev Biol 88: 103-137.

Uhlenhaut NH, Barish GD, Yu RT, Downes M, Karunasiri M, Liddle C, Schwalie P, Hubner N, Evans RM. 2013. Insights into negative regulation by the glucocorticoid receptor from genome-wide profiling of inflammatory cistromes. Mol Cell 49: 158-171.

van de Ven C, Bialecka M, Neijts R, Young T, Rowland JE, Stringer EJ, Van Rooijen C, Meijlink F, Nóvoa A, Freund JN, et al. 2011. Concerted involvement of $\mathrm{Cdx} /$ Hox genes and Wnt signaling in morphogenesis of the caudal neural tube and cloacal derivatives from the posterior growth zone. Development 138: 3451-3462.

van Rooijen C, Simmini S, Bialecka M, Neijts R, van de Ven C, Beck F, Deschamps J. 2012. Evolutionarily conserved requirement of Cdx for post-occipital tissue emergence. Development 139: 2576-2583.

Vitobello A, Ferretti E, Lampe X, Vilain N, Ducret S, Ori M, Spetz J, Selleri L, Rijli FM. 2011. Hox and Pbx factors control retinoic acid synthesis during hindbrain segmentation. Dev Cell 20: 469-482.

Wada H, Garcia-Fernàndez J, Holland PW. 1999. Colinear and segmental expression of amphioxus Hox genes. Dev Biol 213: 131-141.

Wellik DM. 2009. Hox genes and vertebrate axial pattern. Curr Top Dev Biol 88: $257-278$

White RJ, Schilling TF. 2008. How degrading: Cyp26s in hindbrain development. Dev Dyn 237: 2775-2790.

Wobus AM, Kaomei G, Shan J, Wellner MC, Rohwedel J, Ji G, Fleischmann B, Katus HA, Hescheler J, Franz WM. 1997. Retinoic acid accelerates embryonic stem cell-derived cardiac differentiation and enhances development of ventricular cardiomyocytes. J Mol Cell Cardiol 29: 1525-1539.

Young T, Rowland JE, van de Ven C, Bialecka M, Novoa A, Carapuco M, van Nes J, de Graaff W, Duluc I, Freund JN, et al. 2009. Cdx and Hox genes differentially regulate posterior axial growth in mammalian embryos. Dev Cell 17: 516-526.

Zhang X, Lian Z, Padden C, Gerstein MB, Rozowsky J, Snyder M, Gingeras TR, Kapranov P, Weissman SM, Newburger PE. 2009. A myelopoiesis-associated regulatory intergenic noncoding RNA transcript within the human HOXA cluster. Blood 113: 2526-2534.

Received September 27, 2014; accepted in revised form May 28, 2015. 


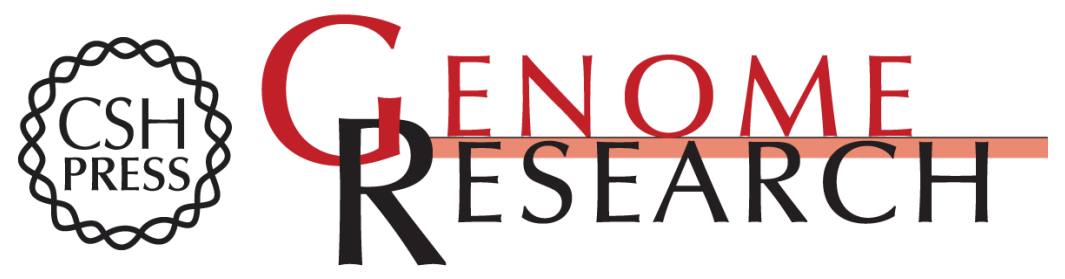

\section{Analysis of dynamic changes in retinoid-induced transcription and epigenetic profiles of murine Hox clusters in ES cells}

Bony De Kumar, Mark E. Parrish, Brian D. Slaughter, et al.

Genome Res. 2015 25: 1229-1243 originally published online May 29, 2015

Access the most recent version at doi:10.1101/gr.184978.114

Supplemental Material

References

Open Access

Creative Commons

License

Email Alerting Service
http://genome.cshlp.org/content/suppl/2015/06/02/gr.184978.114.DC1

This article cites 109 articles, 34 of which can be accessed free at: http://genome.cshlp.org/content/25/8/1229.full.html\#ref-list-1

Freely available online through the Genome Research Open Access option.

This article, published in Genome Research, is available under a Creative Commons License (Attribution 4.0 International), as described at http://creativecommons.org/licenses/by/4.0/.

Receive free email alerts when new articles cite this article - sign up in the box at the top right corner of the article or click here.

\section{Affordable, Accurate Sequencing.}

